\title{
FoxO1 is involved in the antineoplastic effect of calorie restriction
}

\section{Haruyoshi Yamaza ${ }^{1,4}$, Toshimitsu Komatsu ${ }^{1}$, Saori Wakita ${ }^{1}$, Carole Kijogi ${ }^{1}$, Seongjoon Park ${ }^{1}$, Hiroko Hayashi ${ }^{1}$, Takuya Chiba ${ }^{1}$, Ryoichi Mori ${ }^{1}$, Tatsuo Furuyama ${ }^{2}$, Nozomu Mori ${ }^{3}$, Isao Shimokawa ${ }^{1}$}

\footnotetext{
${ }^{1}$ Department of Investigative Pathology, Unit of Basic Medical Science, Graduate School of Biomedical Sciences, Nagasaki University

2 Department of Liberal Arts and Sciences, Kagawa Prefectural College of Health Sciences

${ }^{3}$ Department of Anatomy and Neurobiology, Unit of Basic Medical Science, Graduate School of Biomedical Sciences, Nagasaki University

${ }^{4}$ Present address: Section of Pediatric Dentistry, Division of Oral Health, Growth and Development, Faculty of Dental Science, Kyushu University
}

Correspondence to:

Isao Shimokawa, MD, $\mathrm{PhD}$

Department of Investigative Pathology, Unit of Basic Medical Science, Graduate School of Biomedical Sciences, Nagasaki University

1-12-4 Sakamoto, Nagasaki 852-8523, Japan

E-mail: shimo@nagasaki-u.ac.jp

Phone: $+81-95-819-7051 \quad$ Fax: $+81-95-819-7052$ 
Running title: FoxO1 \& calorie restriction

Key words: Calorie restriction, FoxO, oxidative stress, p21, tumorigenesis, lifespan

Word count: 7969 


\section{Summary}

The FoxO transcription factors may be involved in the antiaging effect of calorie restriction (CR) in mammals. To test the hypothesis, we used FoxO1-knockout heterozygotic (HT) mice, in which the FoxO1 mRNA level was reduced by $50 \%$, or less, of that in wild-type (WT) mouse tissues. The WT and HT mice were fed ad libitum (AL) or $30 \%$ CR diets from 12 weeks of age. Aging- and CR-related changes in body weight, food intake, blood glucose and insulin concentrations were similar between the WT and HT mice in the lifespan study. The response to oxidative stress, induced by intraperitoneal injection of 3-nitropropionic acid (3-NPA), was evaluated in the liver and hippocampus at 6 months of age. Several of the selected FoxO1-target genes for cell cycle arrest, DNA repair, apoptosis, and stress resistance, were up-regulated in the WT-CR tissues after 3-NPA injection, while the effect was mostly diminished in the HT-CR tissues. Of these gene products, we focused on the nuclear p21 protein level in the liver and confirmed its up-regulation only in the WT-CR mice in response to oxidative stress. The lifespan did not differ significantly between the WT and HT mice in AL or CR conditions. However, the antineoplastic effect of $\mathrm{CR}$, as indicated by reduced incidence of tumors at death in the WT-CR mice, was mostly abrogated in the HT-CR mice. The present results suggest a role for FoxO1 in the antineoplastic effect of CR through the induction of genes responsible for protection against oxidative and genotoxic stress. 


\section{Introduction}

Calorie restriction $(\mathrm{CR})$ retards aging processes and extends the lifespan in a wide range of species (Masoro 2005), suggesting the presence of a robust and evolutionarily conserved mechanism that regulates aging and longevity in animals in response to a long-term reduction of calorie intake. Although many researchers are investigating the biological effects of $\mathrm{CR}$, the molecular basis of the presumed mechanism remains incompletely understood.

In the present study, we investigated the role for the forkhead box O1 (FoxO1) transcription factor in the effect of $\mathrm{CR}$ for the following reasons. The FoxO transcription factors, which include FoxO1, 3a, and 4, are mammalian orthologs of Daf-16 in Caenorhabditis elegans (C. elegans; Greer \& Brunet 2005). Daf-16 is required for the lifespan extension in C. elegans, when the daf- 2 or age- 1 gene is mutated and thus the insulin-like signaling is attenuated (Kenyon et al. 1993; Dorman et al. 1995). A classic study in C. elegans (Lakowski \& Hekimi 1998) indicated that the lifespan extension by $\mathrm{CR}$, which was induced by a mutation in the eat- 2 gene, did not require Daf- 16 . However, a recent study has demonstrated a partial necessity for Daf-16 in the effect of CR, when $\mathrm{CR}$ is induced by diluting the number of feeding bacteria (Greer et al. 2007). In mammals, it is also well known that CR reduces the serum levels of insulin and IGF-1 (Masoro 2005).

FoxO transcription factors, which are negatively regulated by signals derived from the growth factor-phosphatidyinositol-3-kinase (PI3K)-protein kinase B (PKB/Akt) pathways, are involved in the up-regulation of a series of target genes that regulate the cell 
cycle, DNA repair, stress resistance and cell survival or apoptosis in response to cellular and genotoxic stress (Furukawa-Hibi et al. 2005; van der Horst \& Burgering 2007). FoxO1 in mammals also promotes hepatic gluconeogenesis during starvation (Daitoku et al. 2003; Barthel et al. 2005). Because of its dual control of stress responses and energy metabolism, FoxO1 may play a role in the effect of CR. In rats, we have reported that $\mathrm{CR}$ attenuates the reduction in FoxO1 binding activity that occurs in response to glucose-stimulated activation of insulin signaling in the liver (Hayashi et al. 2008). However, evidence for the role of FoxO1 in the effects of CR is currently limited.

The present study investigated the potential role for FoxO1 in the effect of CR using FoxO1-knockout heterozygotic (HT) mice (Furuyama et al. 2004), in which the FoxO1 mRNA expression levels are reduced in multiple tissues. We hypothesized that some of the effects of CR are diminished in the HT mice. Therefore, we examined the effects of CR on the glucose-insulin homeostasis and oxidative stress response, both of which characterize the effect of CR, in the HT mice. We also present lifespan and pathological data. To our knowledge, this is the first report that suggests a role for FoxO1 in the antineoplastic effect of CR in mammals in vivo.

\section{Results}

Effect of CR on mRNA expression of FoxO1, 3a, and 4 in selected tissues of WT and HT mice

We investigated the mRNA expression levels of FoxO transcription factors 
(FoxO1, 3a and 4) and housekeeping genes (18S ribosomal RNA, $\beta$-actin and/or cyclophilin) in the liver, spleen, hind-limb skeletal muscle, epididymal white adipose tissue, and hippocampus of 6-month-old (mo) WT and HT mice (Table 1 and Supplemental Table 1).

The mRNA expression levels of FoxO1 in the HT mouse tissues were decreased by $50 \%$, or less, of the respective tissue levels of the control WT mice (Table 1), although this was not statistically significant in the skeletal muscle. The mRNA levels of FoxO3a did not differ between the WT and HT mice in any of the tissues examined (Supplemental Table 1). Furthermore, the mRNA levels of FoxO4 in the HT mouse tissues did not differ from those in the WT mouse tissues, except for epididymal adipose tissue; the FoxO4 mRNA level in this tissue was increased by $20 \%$ in the HT mice (Supplemental Table 1).

The mRNA expression level of FoxO1 was significantly higher in the liver and skeletal muscle in the CR groups than in the AL groups, but not in the other tissues (Table 1). The expression levels of FoxO3a did not differ between the AL and CR groups in any of the tissues (Supplemental Table 1), whereas the level of FoxO4 was increased in the skeletal muscle and adipose tissue in the CR groups.

The mRNA expression levels of $18 \mathrm{~S}$ ribosomal RNA and $\beta$-actin in the liver, spleen, muscle, and adipose tissue, and the expression levels of cyclophilin and $\beta$-actin in the hippocampus remained broadly constant (Table 1).

Body weight and food intake in the WT and HT mice

Body weight gradually increased until 19 mo in the WT-AL and HT-AL mice and started decreasing thereafter (Figure 1A). Body weight did not differ significantly 
between the WT-AL and HT-AL mice. The mean daily food intake in the HT-AL mice was similar to that in the WT-AL mice for most of the lifespan study (Figure 1B), and the amount of food supplied to the WT-CR and HT-CR mice was similar between 12 and 36 weeks of age; thereafter, the same amount of food was supplied to both CR groups until the end of the lifespan study. The body weights of the WT-CR and HT-CR mice subsequently decreased, although only slightly, after the initiation of the CR regimen (Figure 1A), but stayed constant until 24 mo; thereafter, both groups of mice exhibited slight weight loss. There was no difference between the WT-CR and HT-CR mice.

\section{Blood glucose and plasma insulin levels during aging}

The blood glucose concentration, which was slightly lower in the post-prandial phase than in the pre-prandial phase (Phase, $\mathrm{p}<0.0001$ ), decreased gradually between 6 and 24 mo in the WT-AL mice (Age, $p<0.0001$; Figure 2A). The blood glucose level was lower in the WT-CR mice than in the WT-AL mice (Diet, $\mathrm{p}<0.0001$ ), and the age-related reduction in blood glucose was attenuated in the WT-CR mice as compared with that in the WT-AL mice (Diet $\times$ Age, $p<0.0001)$. The blood glucose concentrations in the HT mice were similar to those in the WT mice in terms of the age-related change and the effect of CR, except for slightly lower values in the pre-prandial phase in HT-CR mice at 6 and 12 mo than in the WT-CR mice (Genotype $\times$ Phase, $\mathrm{p}<0.05$ ).

The plasma insulin level was affected by aging and by the feeding phase in the WT-AL and HT-AL mice (Age, $\mathrm{p}<0.0001$; Phase, $\mathrm{p}<0.0001$; Figure 2B). However, there was no significant difference between the WT and HT mice under AL conditions. The plasma insulin level was consistently lower in the pre-prandial phase in the WT-CR and 
HT-CR mice than in the respective AL groups (Diet $\times$ Phase, $\mathrm{p}<0.0001$ ). The post-prandial plasma insulin levels increased gradually between 6 and $24 \mathrm{mo}$ in the CR groups; thus, the insulin levels at 24 mo were greater in the CR groups than in the AL groups (Diet $\times$ Age, $\mathrm{p}<0.0001$; Age $\times$ Phase, $\mathrm{p}<0.001)$. There was no difference between the WT and HT mice under either the AL or CR conditions.

The quantitative insulin sensitivity check index (QUICKI) was also derived from fasting insulin and blood glucose concentrations to evaluate insulin sensitivity or resistance (Figure 2C). Overall, the QUICKI was greater in the HT mice than in the WT mice (Genotype, $p=0.0076$ ), suggesting an increment in insulin sensitivity in the HT mice. The QUICKI was also greater in the CR groups than in the AL groups (Diet, $\mathrm{p}=$ 0.0055). Age-related changes in the QUICKI differed between the WT and HT mice (Genotype $\times$ Age, $p=0.0444)$ and between the AL and CR groups (Diet $\times$ Age, $p=$ 0.0012). In the WT-AL, WT-CR, and HT-CR mice, the QUICKI did not significantly change with age. However, in the HT-AL mice, the QUICKI was greater at 24 mo than at 6 and 12 mo.

Effects of CR on the mRNA expression levels of selected genes in response to oxidative stress in the liver and hippocampus

We selected the liver and hippocampus to examine the effect of CR on the mRNA expression of selected FoxO1 target genes involved in cell cycle arrest, DNA damage/repair, apoptosis, and the stress response, because these tissues show differences in terms of cell renewal during aging; most cells are slowly renewed in the liver, whereas most neurons in the hippocampus stay in a post-mitotic state. In addition, the mRNA level 
of FoxO1 was up-regulated in the HT mouse liver by $\mathrm{CR}$, but not in the HT hippocampus (Table 1).

The mRNA expression levels of $\beta$-actin in the liver were not significantly affected by the diet, genotype or time (Table 2; Supplemental Figure 1A). The cyclophilin mRNA levels in the hippocampus did not significantly change over time and were similar in the diet and genotype groups (Table 2; Supplemental Figure 1B).

By contrast with the housekeeping genes, the mRNA levels of most of the FoxO1 target genes (except for catalase) were up-regulated in the liver of the CR groups compared with that in the AL groups at one or multiple times (Table 2; Figure 3; Supplemental Figure 2). In the hippocampus, the mRNA expression levels of p21 and Txnip were greater in the CR groups than in the AL groups (Table 2; Figures 3B and 3J), while the mRNA levels of catalase were slightly lower in the CR groups (Table 2; Supplemental Figure 2D). There was no significant difference in the levels of Gadd $45 \alpha$, Bim, sod 2 or p27 between the AL and CR groups in the hippocampus (Figures 3D, 3F, 3H; Supplemental Figure 2B).

Changes in the mRNA expression levels in the HT-CR mouse tissues were considerably different from those in the WT-CR mouse tissues (Genotype $\times$ Diet, $p<0.05$ or $\mathrm{p}<0.10$ in Table 2 or $\mathrm{p}<0.05$ by unpaired t-test in Figure 3 ). The up-regulation of $\mathrm{p} 21$ mRNA levels observed at 60 or $240 \mathrm{~min}$ in the WT-CR tissues was not apparent in the HT-CR tissues (Figure 3A, 3B). The Gadd45 $\alpha$ mRNA expression levels were generally not significantly different between the WT-AL and WT-CR liver, although the level was significantly greater in the HT-AL tissue at 30 min than in the corresponding WT-AL tissue (Figure 3C). The Gadd45 $\alpha$ mRNA expression levels were increased at $240 \mathrm{~min}$ in 
the hippocampus of the WT AL and CR mice, but not in the HT mice (Figure 3D). The Bim mRNA expression levels were increased at $60 \mathrm{~min}$ in the liver of WT-CR mice, but not in the HT-CR mice (Figure 3E). The sod2 mRNA expression levels were greater in the WT-CR liver than those in the WT-AL liver, but there was no difference between the HT-AL and HT-CR liver (Figure 3G). The Txnip mRNA expression levels were increased at $60 \mathrm{~min}$ in the hippocampus of WT-CR mice, but not in the HT-CR mice (Figure 3J). Finally, the p27 mRNA levels were greater throughout the duration of the experiment in the WT-CR liver, but not in the HT-CR liver (Supplemental Figure 2A).

\section{Nuclear FoxO1 and p21 expression levels in the liver}

Since FoxO1 is reported to enter the nucleus in response to oxidative stress (Furukawa-Hibi et al. 2005) and thus induce the transcription of its target genes, the protein level of FoxO1 in the hepatic nuclear fraction was measured by Western blotting. Overall, the protein abundance of FoxO1 was greater at $60 \mathrm{~min}$ than at 0 and $240 \mathrm{~min}$ (Time, $\mathrm{p}=0.0008 ; 0 \min \mathrm{vs} 60 \min \mathrm{p}<0.01,60 \min \mathrm{vs} 240 \mathrm{~min}, \mathrm{p}<0.01$ ); there was no difference between 0 and $240 \mathrm{~min}$. The protein level was greater in the WT mice (Figure 4A, B; Genotype, $p=0.0268$ ), and in the CR groups (Diet, $p=0.0004)$. In particular, the FoxO1 level was much lower in the HT-CR mice than in the WT-CR mice at 0 min, athough the level was not statistically different at 60 and $240 \mathrm{~min}$.

The hepatic nuclear $\mathrm{p} 21$ protein level was also examined because the mRNA expression level of p21 was significantly greater at $240 \mathrm{~min}$ in the WT-CR (Figure 3A). Western blotting only showed positive signals in the WT-CR group at $240 \mathrm{~min}$ (Figure 5A, B). 
Longevity and pathology

The survival curves of the CR groups were significantly different from those of the AL groups. However, the survival curves of HT mice did not differ significantly from those of the WT mice, in either the AL or CR condition (Figure 6). The 25th percentile for survival was $34.7 \%$ and $42.7 \%$ greater for the WT-CR and HT-CR mice compared with the respective AL groups (Table 3).

According to autopsy findings, 13 out of 17 WT-AL mice were judged to die due to neoplasms (Table 4). By contrast, only three out of 18 WT-CR mice died due to neoplasms. Thus, the proportion of deaths due to neoplasms was lower in the WT-CR mice. The proportion of mice with tumors at death was also lower in the WT-CR mice than the WT-AL mice. Of note, the prevalence of malignant lymphoma was lower in the WT-CR mice than in the WT-AL mice. These data support the antineoplastic effect of CR. The incidence of tumors in each group is also shown in Supplemental Table 2.

The proportion of deaths due to neoplasms and the proportion of mice with tumors at death did not differ between the WT-AL and HT-AL mice (Table 4). Furthermore, the prevalence of malignant lymphoma did not differ between the WT-AL and HT-AL mice. Ten out of 18 HT-CR mice were judged to die due to neoplasms. This proportion was not significantly different from that of HT-AL mice. The proportion was also greater than that of WT-CR mice. In addition, the proportion of mice with tumors at death was not different between the HT-CR and HT-AL mice. The prevalence of malignant lymphoma did not differ significantly between the HT-AL and HT-CR mice. 


\section{Discussion}

The present study has shown that CR up-regulates some genes involved in cell cycle arrest (e.g., p21), DNA repair (Gadd45 $\alpha)$, apoptosis (Bim) and the stress response (sod2) in response to oxidative stress in the liver and/or the hippocampus. This effect was diminished in the tissues of HT mice. These findings suggest that FoxO1 is involved in the CR-specific response to oxidative stress. Oxidative stress impairs genomic integrity, leading to the progression of age-related diseases such as cancer, even though organisms have evolved protective mechanisms. CR may enhance these presumed protective mechanisms. Indeed, the global DNA repair and the transcription-coupled DNA repair processes, both of which are reduced with advancing age, are maintained in CR rodents (Rao 2003). Therefore, it is plausible that CR effectively induces these protective mechanisms in response to oxidative and, thus, genotoxic stress, and at least partly depends on a FoxO1-associated transcriptional mechanism.

The present study has shown that $\mathrm{CR}$ altered the FoxO1 mRNA expression level in a tissue-dependent manner. However, the mRNA level of FoxO1 may not represent its transcriptional activity. The activity of Foxo1 is subject to post-translational modifications including phosphorylation, acetylation and ubiquitylation (van der Horst, 2007). Akt-mediated phosphorylation of FoxO1 inhibits FoxO1 activity through nuclear exclusion; by contrast, oxidative stress-associated phosphorylation of FoxO1 promotes the translocation of FoxO1 into the nucleus and activates the transcription of FoxO1 target genes (Furukawa-Hibi et al. 2005; van der Horst, 2007). Oxidative stress is also reported to regulate the activity of FoxO1 by acetylation (van der Horst, 2007). In the present study, 
we confirmed that FoxO1 was decreased in the hepatic nucleus in the HT mice, whereas CR up-regulated the overall protein level. However, we did not detect significant differences in the nuclear levels of FoxO1 in the liver after oxidative stress between the WT-CR and the HT-CR mice. Therefore, site-specific modifications of FoxO1 and its transcriptional activity should be further evaluated under CR conditions.

In parallel with the changes in gene expression in response to oxidative stress, the present pathologic analysis revealed that the antineoplastic effect of CR was mostly abrogated in the HT mice. Thus, our data suggest that CR exhibits an antineoplastic effect by regulating FoxO1-target genes involved in cell cycle arrest for DNA damage/repair and apoptosis.

The present results mirror a study by Kalaany \& Sabatini (2009), who reported that human cancer cell lines, which were insensitive to the antigrowth effect of CR when grown as tumor xenografts in mice, carried mutations causing constitutive activation of the PI3K-Akt pathway. In those cells, FoxO1 was mostly sequestered in the cytoplasm. Furthermore, a FoxO1-overexpressing cell line showed greater responses to CR. Immunohistochemical analyses also showed nuclear localization of FoxO1 in those cells after CR. Their experiments clearly indicate the necessity for an intact PI3K-Akt-FoxO1 pathway in the antineoplastic effect of CR.

The present study focused on p21 to support the presumption described above. In response to oxidative stress, the gene expression and hepatic nuclear protein levels of p21 were increased in the WT-CR mice, but not in the HT-CR mice. p21 is known to be involved in tumor suppression by p53 through the induction of cell cycle arrest by inhibition of cyclin dependent kinases (Kastan \& Bartek 2004). Accordingly, p21-deficient 
mice were reported to develop a variety of spontaneous tumors including malignant lymphoma at earlier ages than wild type mice (Martin-Caballero et al. 2001). These findings suggest a link between the up-regulation of p21 in the CR mouse tissues in response to oxidative stress and inhibition of tumorigenesis by $\mathrm{CR}$ in a FoxO1-dependent manner.

NF-E2-related factor 2 (Nrf2)-KO mice were also reported to show findings similar to those in the FoxO1-HT mice under CR conditions (Pearson et al. 2008). In Nrf2-KO mice, CR increased the lifespan, similar to that in WT mice, while CR was unable to suppress chemically induced tumorigenesis. Nrf2 is a transcription factor that binds to the antioxidant response element of target genes in response to oxidative stress, and promotes the gene expression of a variety of antioxidative and carcinogen-detoxification enzymes (Ishii et al. 2002; Kobayashi \& Yamamoto 2006). Intriguingly, a recent study revealed an interplay between p21 and Nrf2 (Chen et al. 2009). In response to oxidative stress, $\mathrm{p} 21$ directly interacts with $\mathrm{Nrf} 2$ and potentiates the transcriptional activity of $\mathrm{Nrf} 2$ to its target genes that are essential for thiol redox control and elimination of reactive oxygen species.

The present study demonstrated that partial loss of FoxO1 had no significant effect on spontaneous tumorigenesis or longevity under AL feeding conditions. Additional knockout of FoxO3a and 4 genes was previously reported to decrease the lifespan (Castrillon et al. 2003; Tothova et al. 2007). Mice, in which all three FoxO genes were conditionally deleted in the adult stage, developed aggressive lymphoma and wide-spread hemangioma, whereas mice bearing single or compound germline FoxO null mutations revealed remarkably mild cancer predisposition phenotypes as a function of advancing age 
or in response to exposure to carcinogens (Paik et al. 2007). These findings are interpreted as a redundancy and developmental compensation of FoxO1, 3a and 4 under AL conditions. However, the present study showed that even a partial loss of FoxO1 affected the induction of stress response genes and the development of spontaneous tumors under CR conditions. Because the FoxO transcription factor family has evolved in response to famine or food shortage that frequently occur in nature, it is reasonable to consider that the original or main function of FoxO1 is tangible only during $\mathrm{CR}$, although the potential role of FoxO3a and/or FoxO4 under CR conditions remains to be elucidated.

In this study, the lifespan of HT-CR mice did not differ from that of WT-CR mice, although more mice died as a result of neoplasms. The results imply that non-neoplastic death, and thus the progression of aging, was probably delayed in the HT-CR mice. p53, a transcription factor that up-regulates p21 in response to oxidative or genotoxic stress, can protect cells from death and also induce cells to undergo cell death, depending on the level of DNA damage and the cell type (Garner \& Raj 2008). Increased p53 activity was reported to shorten the lifespan of mice, although it also induced tumor resistance (Tyner et al. 2002). By contrast, reduced neuronal p53 activity extended the lifespan of flies (Bauer et al. 2005). In a mouse model with premature aging due to dysfunctional telomeres, the deletion of p21 increased the median lifespan without increasing tumor incidence (Choudhury et al. 2007). Thus, the attenuated transcriptional response of p21 might have a benefit on the aging process during CR. Accordingly, mammalian FoxO1 may be involved in a trade-off between aging and neoplastic processes.

FoxO1 in mammals controls the gluconeogenesis pathway, which stimulates 
hepatic gluconeogenesis during periods of CR/starvation (Daitoku et al. 2003; Barthel et al. 2005). In our lifespan study, body weight and food intake were similar in WT and HT mice under AL or CR conditions. Blood glucose and insulin concentrations were affected by aging, feeding phase and CR. However, the glucose and insulin profiles were similar to those in WT mice during the normal feeding conditions for the AL and CR groups; the QUICKI suggested a slight increment in insulin sensitivity in HT mice, particularly those fed AL. Thus, it seems that a partial loss of FoxO1 slightly affects age-related insulin resistance and altered energy metabolism, particularly under AL conditions. However, the effect was limited during CR.

In summary, the results of the present study indicate a role for FoxO1 in the stress response and in the antineoplastic effect of CR in rodents. The potential role of FoxO1 in the non-neoplastic aging process and the roles of other FoxO family members in the effect of CR should be investigated.

\section{Experimental procedures}

\section{Animals}

The present study was conducted in accordance with the provisions of the Ethics Review Committee for Animal Experimentation at Nagasaki University. FoxO1-HT mice, were generated and backcrossed onto a C57BL/6J background at the National Institute of Longevity Sciences (Obu, Aichi, Japan), and were transferred to the Laboratory Animal Center for Biomedical Research at the Center for Frontier Life Sciences at Nagasaki University. Homozygotes were embryonic lethal (Furuyama et al. 2004). WT female mice 
of the same genetic background were purchased from Japan Clea Inc. (Tokyo, Japan). Male HT mice and female WT mice were mated to produce HT and WT mice for the present experiment. A tail biopsy was performed in weanling mice for genotyping by PCR with specific primers (Furuyama et al. 2004).

Mice were housed individually in a barrier facility (temperature, $22-25^{\circ} \mathrm{C}$; 12-h light/dark cycle) under specific pathogen-free conditions, which was maintained for the entire study. Sentinel animals were sent for bacterial and viral testing every 3 months, as described elsewhere (Shimokawa et al. 2002).

All mice were fed AL with Charles River-LPF diet (Oriental Yeast Co. Ltd., Tsukuba, Japan), which has been used for over 10 years in our laboratory as a standard food for long-term studies, including CR regimens in rats and mice (Shimokawa et al. 2002; Shimokawa et al. 2003). At 12 weeks of age, the mice were divided into the AL and CR groups. The CR group was provided with a food allotment consisting of $70 \%$ of the mean daily food intake of the AL group of the WT or HT mice every day, 30 min before lights were turned off; on Saturday, two allotments of food for Saturday and Sunday were provided. The food allotments for the CR groups in the WT and HT mice were adjusted depending on the amount of food consumed by the AL groups every 2 weeks, until 36 weeks of age. As shown in Figure 1, the food intake in HT-AL mice was similar to that in WT-AL mice during the study; thus the food allotments for the CR groups were comparable in the WT and HT mice until 36 weeks of age. In the lifespan study, the amount of food supplied for the CR groups was fixed at the same level after 36 weeks of age. Body weight was monitored every 2 weeks between 6 and 20 weeks of age and every 4 weeks thereafter. 
At 6 mo, mice were decapitated, and tissues including liver, spleen, hind-limb muscle, epididymal white adipose tissue and brain were collected for analysis of FoxO1, 3a, and 4 mRNA expression levels. All tissues, except for the brain, were immediately frozen in liquid nitrogen and stored at $-80^{\circ} \mathrm{C}$ until assayed. The brain was dissected into the frontal, middle and occipital parts on a dissecting device on ice, frozen with dry ice powder, and stored at $-80^{\circ}$ C. Hippocampus tissues were excised from the middle part of the brain and soaked in pre-chilled RNAlater ${ }^{\circledR}-\mathrm{ICE}$ (Ambion, Inc., Austin, TX, USA) at $20^{\circ} \mathrm{C}$ for at least $16 \mathrm{~h}$ to isolate total RNA.

\section{Oxidative stress response experiments}

At 6 mo, mice were killed by decapitation at $0,15,30,60$ or 240 min after intraperitoneal injection of NPA (30 mg/kg body weight), which is an inhibitor of succinate dehydrogenase (Gould et al. 1985) and induces oxidative stress of mitochondrial origin (Fu et al. 1995). Tissues were immediately collected, frozen in liquid nitrogen, and stored at $-80^{\circ} \mathrm{C}$ until assayed.

\section{Real time PCR}

Total RNA was purified from the liver and hippocampus tissues, as previously described (Chiba et al. 2008). The quality of extracted RNA was evaluated as the densitometric ratio of $28 \mathrm{~S}$ and $16 \mathrm{~S}$ ribosomal RNA. The extracted RNA was reverse-transcribed using a Bio-Rad reverse transcriptase reagent kit (Hercules, USA) according to the manufacturer's instructions. Real-time PCR analysis of selected genes involved in cell cycle arrest and DNA repair (p21, p27 and Gadd45 $\alpha$ ), apoptosis (Bim), 
stress resistance (sod2, catalase, Txnip) and control housekeeping genes ( $ß$-actin, 18S ribosomal RNA and cyclophilin) was performed as previously described (Yamaza et al. 2007). All of the primers and probes used in the present analysis were purchased from Applied Biosystems with reference to the TaqMan ${ }^{\circledR}$ Gene Expression Assay library (Applied Biosystems, Tokyo, Japan).

All samples and standard curves were tested in triplicate. We confirmed that the housekeeping genes were not significantly affected by the diet or the genotype in most cases, but not all. Thus, we decided not to normalize the expression levels of specific genes to those of the housekeeping genes. When normalized, the statistical results were almost same.

\section{Western blot analysis}

To extract nuclear protein from liver, a modified fractionation protocol was used, as previously described (Corsini et al., 1997). All procedures were performed at $4^{\circ} \mathrm{C}$. Briefly, $200 \mathrm{mg}$ of liver was homogenized for $30 \mathrm{~s}$ in $1.2 \mathrm{ml}$ of cold hypotonic lysis buffer (buffer A: 10 mM Hepes pH 7.8, $10 \mathrm{mM} \mathrm{KCl,} 2$ mM MgCl 2,1 mM DTT, 0.1 mM EDTA, 0.1 mM PMSF, $0.5 \mu \mathrm{g} / \mathrm{ml}$ protease inhibitor cocktail (P8340, Sigma-Aldrich, MO, USA), 1x phosphatase inhibitor cocktail (Nacalai tesque, Inc., Japan)) using a tissue homogenizer. After incubating the resulting homogenates on ice for $20 \mathrm{~min}, 150 \mu 1$ of $10 \% \mathrm{NP}-40$ solution was added and mixed for $15 \mathrm{~s}$. The mixture was centrifuged at $13,000 \mathrm{x}$ g for 2 min. The pelleted nuclei were washed twice with $200 \mu$ l of buffer A plus $25 \mu 1$ of $10 \%$ NP-40, and centrifuged at $13,000 \mathrm{x}$ g for $30 \mathrm{~s}$. The pellet was re-suspended in $100 \mu \mathrm{l}$ of buffer B (50 mM Hepes pH 7.8, 50 mM KCl, 300 mM NaCl, 0.1 mM EDTA, 1 mM DTT, 
$0.1 \mathrm{mM}$ PMSF, $0.5 \mu \mathrm{g} / \mathrm{ml}$ protease inhibitor cocktail, $1 \mathrm{x}$ phosphatase inhibitor cocktail, $10 \%$ (vol/vol) glycerol), mixed for $30 \mathrm{~min}$ and centrifuged at $13,000 \mathrm{x} \mathrm{g}$ for $10 \mathrm{~min}$. After harvesting the supernatant containing nuclear proteins, the protein concentration was determined using a BCA assay kit (PIERCE Biotechnology, Rockford, IL). The supernatant was aliquoted and stored at $-80^{\circ} \mathrm{C}$ until used for Western blotting.

The antibody to FoxO1 (sc-11350) was obtained from Santa Cruz Biotechnology (CA, USA). Antibodies to p21 (ab7960) and TATA binding protein (TBP, ab818) were purchased from Abcam PLC. (Cambridge, UK). The Enhanced Chemiluminescence (ECL) Plus Western blotting detection reagents and ECL anti-rabbit or anti-mouse IgG, horseradish peroxidase-linked species-specific antibodies were purchased from Amersham Pharmacia Biotech (Little Chalfont, UK). Polyvinylidene fluoride (PVDF) membranes were purchased from Millipore (Billerica, MA). The 12.5\% SDS-polyacrylamide gel and running buffer were purchased from DRC Co., Ltd. (Tokyo, Japan). All other chemicals were obtained from Sigma Chemical Co. (MO, USA).

All samples were mixed with Laemmli sample buffer, and heated at $95^{\circ} \mathrm{C}$ for 5 min. For FoxO1 or p21, $9 \mu \mathrm{g}$ or $20 \mu \mathrm{g}$ of protein was loaded onto $12.5 \%$ SDS-PAGE gels, separated, and transferred to a PVDF membrane. The membranes were immediately placed in blocking solution ( $0.3 \%$ non-fat dried milk in TBS-T buffer for $\mathrm{p} 21$ or $3 \%$ for other antibodies) for $1 \mathrm{~h}$, and incubated with the primary antibody for $1 \mathrm{~h}$. The secondary antibody was added and incubated for $1 \mathrm{~h}$. All incubations were at room temperature. The blots were developed with the ECL-Plus kit in accordance with the manufacturer's instructions. The bands were detected using Fluorchem (DE500-5T, Alphainnotech Corporation, San Leandro, CA, USA). The specific signals were quantified using 
MultiGauge ver 3.0 (Fujifilm, Tokyo, Japan). To minimize variations in signal intensity between the blots, a standard sample for FoxO1 was prepared from a 3-NPA-treated wild-type CR mouse, and included in each blot. A standard sample for p21 was prepared from mouse hepatocyte culture cells. Immunoblots for TBP and Ponceau S staining of PVDF membranes were performed to confirm the quality and quantity of loaded samples. Although the protein abundance of TBP in the hepatic nuclear fraction fluctuated after 3-NPA administration, quantitative analyses of the bands stained by Ponceau S confirmed the quality and quantity of nuclear proteins applied to Western blots for FoxO1 and p21 (Supplemental Figure 3).

\section{Longevity study}

The following numbers of mice born within 1 month from the start of April, 2005, were used in the longevity study: WT-AL, 19; WT-CR, 23; HT-AL, 25; and HT-CR, 20. All animals were inspected daily between Monday and Saturday until spontaneous death. Body weight and food intake were monitored as described above. At 6, 12, 18 and 24 mo, a retro-orbital blood sample was collected from mice to measure blood glucose and plasma insulin concentrations. Insulin resistance was evaluated by the quantitative insulin sensitivity check index (QUICKI; Muniyappa et al. 2007), by measuring overnight fasting glucose and insulin concentrations. These blood samples were immediately used for determination of blood glucose levels with an ACCUCHEK Active glucose meter (Roche Diagnostics GmbH, Tokyo, Japan). Fifty- $\mu$ l-aliquots of plasma were stored at $-80^{\circ} \mathrm{C}$ until assayed for insulin concentrations. The plasma insulin concentration was measured using an enzyme-linked immunosorbent assay kit for mouse insulin (EZRMI-13K, Linco 
Research Inc., St. Charles, MO, USA).

\section{Pathological examination}

Dead mice were removed from the cage and autopsied. A few cases were omitted from the present analysis due to severe autolysis. Organs and tissues (brain, heart, lung, liver, pancreas, spleen, kidney, testis, femoral muscle and femoral bone) were excised, fixed in 10\% formalin, and routinely processed for histopathological examination. Other tissues were also examined if gross inspection revealed lesions. The probable cause of death was determined based on gross and histopathological findings, as previously reported (Shimokawa et al. 1991; Shimokawa et al. 2002).

\section{Statistical analysis}

Data are presented as means \pm standard error unless otherwise noted. Body weight, food intake, blood glucose and plasma insulin were analyzed by three-factor analysis of variance (ANOVA) for the effects of diet, genotype, age, and/ or feeding phase and their interaction (noted in the text by Diet, Genotype, Age or Phase, or their combination, with a $\mathrm{p}$ value if needed). mRNA and protein expression levels were analyzed by two- or three-factor ANOVA for the effects of diet and genotype and/or time or their interaction (noted in the text by Diet, Genotype and/or Time, or their combination, with a $p$ value if needed). Unpaired t-tests were used to test for differences between two means. Data were log-transformed for analyses if the assumption of equal variances was violated. Survival curves were estimated using the Kaplan-Meier method, and were compared with the log-rank test. The frequency of causes of death, the proportion of mice 
bearing tumors, and the prevalence of malignant lymphoma were analyzed using $\chi 2$ tests or Fisher's exact test. All statistical analyses were performed using StatView 5.0 software (SAS Institute Inc., Cary, NC). P values of less than 0.05 were considered to be statistically significant; $p$ values of less than 0.10 were also noted as required to indicate tendencies.

\section{Acknowledgments}

We are grateful to the staff at the Laboratory Animal Center for Biomedical Research at the Center for Frontier Life Sciences, Nagasaki University for animal care and technical assistance. We also thank Yutaka Araki, Yuko Moriyama, and Rieko Tahara for their excellent technical assistance. The study was supported by Grants-in-Aid for Scientific Research from the Japan Society for the Promotion of Science (Nos. 15390128, 16790226 and 20790260).

\section{Author contributions}

HY and TK performed most of the experiments and the statistical analyses, and wrote the first draft of the paper. SW and CK performed most of the RT-PCR analyses. SP, HH, TC and RM served as advisors for the pathological analysis, animal care, oxidative stress and longevity studies. TF and NM developed the HT mice and provided knowledge of genotyping and animal care. IS was the overall director of the research, provided the funds for the research (HY and RM also provided some funds), and contributed to the writing 
and editing of this manuscript.

\section{References}

Barthel A, Schmoll D, Unterman TG (2005). FoxO proteins in insulin action and metabolism. Trends Endocrinol Metab. 16, 183-189.

Bauer JH, Poon PC, Glatt-Deeley H, Abrams JM, Helfand SL (2005). Neuronal expression of p53 dominant-negative proteins in adult Drosophila melanogaster extends life span. Curr Biol. 15, 2063-2068.

Castrillon DH, Miao L, Kollipara R, Horner JW, DePinho RA (2003). Suppression of ovarian follicle activation in mice by the transcription factor Foxo3a. Science. 301, $215-218$.

Chen W, Sun Z, Wang X-J, Jiang T, Huang Z, Fang D, Zhang DD (2009). Direct interaction between Nrf2 and p21Cip/WAF1 upregulates the Nrf2-mediated antioxidant response. Mol Cell 34, 663-673.

Chiba T, Yamaza H, Komatsu T, Nakayama M, Fujita S, Hayashi H, Higami Y, Shimokawa I (2008). Pituitary growth hormone suppression reduces resistin expression and enhances insulin effectiveness: relationship with caloric restriction. Exp Gerontol. 43, 595-600. 
Daitoku H, Yamagata K, Matsuzaki H, Hatta M, Fukamizu A (2003). Regulation of PGC-1 promoter activity by protein kinase B and the forkhead transcription factor FKHR.

Diabetes. 52, 642-649.

Dorman JB, Albinder B, Shroyer T, Kenyon C (1995). The age-1 and daf-2 genes function in a common pathway to control the lifespan of Caenorhabditis elegans. Genetics. 141, 1399-1406.

Fu YT, He FS, Zhang SL, Zhang JS (1995). Lipid peroxidation in rats intoxicated with 3-nitropropionic acid. Toxicon. 33, 327-331.

Furukawa-Hibi Y, Kobayashi Y, Chen C, Motoyama N (2005). FOXO transcription factors in cell-cycle regulation and the response to oxidative stress. Antioxid Redox Signal. 7, $752-760$.

Furuyama T, Kitayama K, Shimoda Y, Ogawa M, Sone K, Yoshida-Araki K, Hisatsune H, Nishikawa S, Nakayama K, Nakayama K, Ikeda K, Motoyama N, Mori N (2004). Abnormal angiogenesis in Foxo1 (Fkhr)-deficient mice. J Biol Chem. 279, 34741-34749.

Garner E, Raj K (2008). Protective mechanisms of p53-p21-pRb proteins against DNA damage-induced cell death. Cell Cycle. 7, 277-282.

Gould DH, Wilson MP, Hamar DW (1985). Brain enzyme and clinical alterations induced 
in rats and mice by nitroaliphatic toxicants. Toxicol Lett. 27, 83-89.

Greer EL, Brunet A (2005). FOXO transcription factors at the interface between longevity and tumor suppression. Oncogene. 24, 7410-7425.

Greer EL, Dowlatshahi D, Banko MR, Villen J, Hoang K, Blanchard D, Gygi SP, Brunet A (2007). An AMPK-FOXO pathway mediates longevity induced by a novel method of dietary restriction in C. elegans. Curr Biol. 17, 1646-1656.

Hayashi H, Yamaza H, Komatsu T, Park S, Chiba T, Higami Y, Nagayasu T, Shimokawa I (2008). Calorie restriction minimizes activation of insulin signaling in response to glucose: potential involvement of the growth hormone-insulin-like growth factor 1 axis. Exp Gerontol. 43, 827-832.

Ishii T, Itoh K, Yamamoto M (2002). Roles of Nrf2 in activation of antioxidant enzyme genes via antioxidant responsive elements. Methods Enzymol. 348, 182-190.

Kalaany NY, Sabatini DM (2009). Tumours with PI3K activation are resistant to dietary restriction. Nature. $458,725-731$.

Kastan MB, Bartek J (2004). Cell-cycle checkpoints and cancer. Nature. 432, 316-323.

Muniyappa R, Lee S, Chen H, Quon MJ (2007). Current approaches for assessing insulin 
sensitivity and resistance in vivo: advantages, limitations, and appropriate usage. Am J Physiol Endocrinol Metab 294, E15-E26.

Kenyon C, Chang J, Gensch E, Rudner A, Tabtiang R (1993). A C. elegans mutant that lives twice as long as wild type. Nature. 366, 461-464.

Kobayashi M, Yamamoto M (2006). Nrf2-Keap1 regulation of cellular defense mechanisms against electrophiles and reactive oxygen species. Adv Enzyme Regul. 46, 113-140.

Lakowski B, Hekimi S (1998). The genetics of caloric restriction in Caenorhabditis elegans. Proc Natl Acad Sci U S A. 95, 13091-13096.

Martin-Caballero J, Flores JM, Garcia-Palencia P, Serrano M (2001). Tumor susceptibility of p21 ${ }^{\text {Wafl/Cip1 }}$-deficient mice. Cancer Res. 61, 6234-6238.

Masoro EJ (2005). Overview of caloric restriction and ageing. Mech Ageing Dev. 126, 913-922.

Paik JH, Kollipara R, Chu G, Ji H, Xiao Y, Ding Z, Miao L, Tothova Z, Horner JW, Carrasco DR, Jiang S, Gilliland DG, Chin L, Wong WH, Castrillon DH, DePinho RA (2007). FoxOs are lineage-restricted redundant tumor suppressors and regulate endothelial cell homeostasis. Cell. 128, 309-323. 
Pearson KJ, Lewis KN, Price NL, Chang JW, Perez E, Cascajo MV, Tamashiro KL, Poosala S, Csiszar A, Ungvari Z, Kensler TW, Yamamoto M, Egan JM, Longo DL, Ingram DK, Navas P, de Cabo R (2008). Nrf2 mediates cancer protection but not prolongevity induced by caloric restriction. Proc Natl Acad Sci USA. 105, 2325-2330.

Rao KS (2003). Dietary calorie restriction, DNA-repair and brain aging. Mol Cell Biochem. 253, 313-318.

Shimokawa I, Higami Y, Tsuchiya T, Otani H, Komatsu T, Chiba T, Yamaza H (2003). Life span extension by reduction of the growth hormone-insulin-like growth factor-1 axis: relation to caloric restriction. FASEB J. 17, 1108-1109.

Shimokawa I, Higami Y, Utsuyama M, Tuchiya T, Komatsu T, Chiba T, Yamaza H (2002). Life span extension by reduction in growth hormone-insulin-like growth factor-1 axis in a transgenic rat model. Am J Pathol. 160, 2259-2265.

Shimokawa I, Yu BP, Masoro EJ (1991). Influence of diet on fatal neoplastic disease in male Fischer 344 rats. J Gerontol. 46, B228-232.

Tothova Z, Kollipara R, Huntly BJ, Lee BH, Castrillon DH, Cullen DE, McDowell EP, Lazo-Kallanian S, Williams IR, Sears C, Armstrong SA, Passegue E, DePinho RA, Gilliland DG (2007). FoxOs are critical mediators of hematopoietic stem cell resistance to physiologic oxidative stress. Cell. 128, 325-339. 
Tyner SD, Venkatachalam S, Choi J, Jones S, Ghebranious N, Igelmann H, Lu X, Soron G, Cooper B, Brayton C, Hee Park S, Thompson T, Karsenty G, Bradley A, Donehower LA (2002). p53 mutant mice that display early ageing-associated phenotypes. Nature. 415, 45-53.

van der Horst A, Burgering BM (2007). Stressing the role of FoxO proteins in lifespan and disease. Nat Rev Mol Cell Biol. 8, 440-450.

Yamaza H, Komatsu T, To K, Toyama H, Chiba T, Higami Y, Shimokawa I (2007).

Involvement of insulin-like growth factor-1 in the effect of caloric restriction: regulation of plasma adiponectin and leptin. J Gerontol A Biol Sci Med Sci. 62, 27-33. 
Table 1. mRNA expression levels of FoxO1 in the selected tissues in wild-type (WT) and FoxO1-KO heterozygotic (HT) mice fed ad libitum (AL) or a calorie-restricted (CR) diet

\begin{tabular}{|c|c|c|c|c|c|c|c|c|}
\hline & & \multicolumn{4}{|c|}{ Group } & \multicolumn{2}{|c|}{$\begin{array}{l}\text { Main effect by } \\
\text { two-factor ANOVA }\end{array}$} & Interaction \\
\hline & & \multirow[t]{2}{*}{ WT-AL } & \multirow[t]{2}{*}{ WT-CR } & \multirow[t]{2}{*}{ HT-AL } & \multirow[t]{2}{*}{ HT-CR } & \multirow[t]{2}{*}{ Genotype } & \multirow[t]{2}{*}{ Diet } & Genotype $\times$ \\
\hline & & & & & & & & Diet \\
\hline \multirow[t]{3}{*}{ Liver } & FoxO1 & $1.00 \pm 0.15$ & $1.27 \pm 0.11$ & $0.36 \pm 0.04$ & $0.89 \pm 0.19$ & $* *$ & $*$ & ns \\
\hline & $18 \mathrm{~S}$ & $1.00 \pm 0.18$ & $1.15 \pm 0.11$ & $1.31 \pm 0.19$ & $1.15 \pm 0.15$ & ns & ns & ns \\
\hline & $\beta$-actin & $1.00 \pm 0.03$ & $1.11 \pm 0.09$ & $1.02 \pm 0.05$ & $1.05 \pm 0.23$ & ns & ns & ns \\
\hline \multirow[t]{3}{*}{ Spleen } & FoxO1 & $1.00 \pm 0.16$ & $0.84 \pm 0.17$ & $0.38 \pm 0.03$ & $0.45 \pm 0.08$ & $* *$ & ns & ns \\
\hline & $18 \mathrm{~S}$ & $1.00 \pm 0.07$ & $0.83 \pm 0.07$ & $1.14 \pm 0.11$ & $1.05 \pm 0.06$ & $*$ & ns & ns \\
\hline & $\beta$-actin & $1.00 \pm 0.06$ & $0.87 \pm 0.11$ & $0.71 \pm 0.03$ & $0.69 \pm 0.03$ & $* *$ & ns & ns \\
\hline
\end{tabular}




\begin{tabular}{|c|c|c|c|c|c|c|c|c|}
\hline \multirow[t]{3}{*}{ Muscle } & FoxO1 & $1.00 \pm 0.22$ & $1.88 \pm 0.55$ & $0.39 \pm 0.05$ & $1.40 \pm 0.43$ & ns & $*$ & ns \\
\hline & $18 \mathrm{~S}$ & $1.00 \pm 0.13$ & $0.90 \pm 0.03$ & $1.07 \pm 0.07$ & $1.21 \pm 0.12$ & $\mathrm{~ns}$ & $\mathrm{~ns}$ & ns \\
\hline & $\beta$-actin & $1.00 \pm 0.25$ & $1.12 \pm 0.17$ & $1.03 \pm 0.20$ & $0.75 \pm 0.05$ & ns & ns & ns \\
\hline \multirow[t]{3}{*}{ lipose tissue } & FoxO1 & $1.00 \pm 0.13$ & $0.90 \pm 0.14$ & $0.50 \pm 0.90$ & $0.64 \pm 0.16$ & $*$ & $\mathrm{~ns}$ & ns \\
\hline & $18 \mathrm{~S}$ & $1.00 \pm 0.07$ & $1.18 \pm 0.09$ & $1.30 \pm 0.14$ & $1.15 \pm 0.06$ & $\mathrm{~ns}$ & $\mathrm{~ns}$ & ns \\
\hline & $\beta$-actin & $1.00 \pm 0.10$ & $0.45 \pm 0.05$ & $1.07 \pm 0.11$ & $0.64 \pm 0.14$ & $\mathrm{~ns}$ & $* * *$ & ns \\
\hline \multirow[t]{3}{*}{ ppocampus } & FoxO1 & $1.00 \pm 0.08$ & $0.98 \pm 0.08$ & $0.45 \pm 0.06$ & $0.50 \pm 0.07$ & $* * *$ & $\mathrm{~ns}$ & ns \\
\hline & Cyclophilin & $1.00 \pm 0.13$ & $0.94 \pm 0.09$ & $0.87 \pm 0.16$ & $1.00 \pm 0.04$ & ns & $\mathrm{ns}$ & ns \\
\hline & $\beta$-actin & $1.00 \pm 0.05$ & $0.91 \pm 0.14$ & $0.90 \pm 0.10$ & $0.90 \pm 0.12$ & ns & $\mathrm{ns}$ & ns \\
\hline
\end{tabular}

Data represent means \pm standard error for 3-6 mice. ns, not significant; ${ }^{*}, \mathrm{p}<0.05 ; * *, \mathrm{p}<0.01 ; * * *, \mathrm{p}<0.001$. 
Table 2. Summary of 3-factor ANOVA for expression of mRNA in response to oxidative stress

\begin{tabular}{|c|c|c|c|c|c|c|}
\hline \multirow[b]{2}{*}{ mRNA } & \multicolumn{3}{|c|}{ Main effects } & \multicolumn{3}{|c|}{ Interaction } \\
\hline & Diet & Genotype & Time & Genotype $\times$ Diet & Genotype $\times$ Time & Diet $\times$ Time \\
\hline$\beta$-actin & $\mathrm{ns} / \mathrm{ns}$ & $\mathrm{ns} / \mathrm{ns}$ & $\mathrm{ns} / * *$ & $\mathrm{~ns} / \mathrm{ns}$ & $\mathrm{ns} / \mathrm{ns}$ & $\mathrm{ns} / \mathrm{ns}$ \\
\hline p21 & $* * * / * * *$ & $\mathrm{~ns} / \mathrm{ns}$ & $* * * / * * *$ & $\mathrm{~ns} / \mathrm{ns}$ & $\mathrm{ns} / * *$ & $* * * / *$ \\
\hline p27 & $* * / \mathrm{ns}$ & $\mathrm{ns} / \mathrm{ns}$ & $* * * / \#$ & $\# / \mathrm{ns}$ & $* / \mathrm{ns}$ & $\mathrm{ns} / \mathrm{ns}$ \\
\hline $\operatorname{Gadd} 45 \alpha$ & $* * * / \mathrm{ns}$ & $\mathrm{ns} / \mathrm{ns}$ & $* * * / *$ & $\# / \mathrm{ns}$ & $* / *$ & $* * * / \mathrm{ns}$ \\
\hline Bim & $* * / \mathrm{ns}$ & $* / \#$ & $* * / *$ & $\mathrm{~ns} / \mathrm{ns}$ & $\mathrm{ns} / \mathrm{ns}$ & $\mathrm{ns} / \mathrm{ns}$ \\
\hline SOD2 & $* * / \mathrm{ns}$ & $\mathrm{ns} / \mathrm{ns}$ & $* * * / \mathrm{ns}$ & $* * / \mathrm{ns}$ & $\mathrm{ns} / \mathrm{ns}$ & $\mathrm{ns} / \mathrm{ns}$ \\
\hline Catalase & $\mathrm{ns} / * *$ & $\mathrm{~ns} / \mathrm{ns}$ & $* / *$ & $* / \mathrm{ns}$ & $\# / \mathrm{ns}$ & $\mathrm{ns} / \mathrm{ns}$ \\
\hline Txnip & $* * * / * * *$ & $\mathrm{~ns} / \mathrm{ns}$ & $* * * / * * *$ & $\mathrm{~ns} / \#$ & $\mathrm{~ns} / \mathrm{ns}$ & $* * * / \mathrm{ns}$ \\
\hline
\end{tabular}

Each cell represents the statistical results for liver/hippocampus. ns, not significant; \#, p $<0.10 ; *, p<0.05 ; * *, p<0.01$;

***, $\mathrm{p}<0.001$. 
Table 3. Summary of lifespan data in wild-type (WT) and FoxO1-KO heterozygotic (HT) mice fed ad libitum (AL) or a calorie-restricted (CR) diet

\begin{tabular}{|c|c|c|c|c|}
\hline & WT-AL & WT-CR & HT-AL & HT-CR \\
\hline Age at 50th percentile survival & $133 \pm 5$ & $167 \pm 4$ & $121 \pm 6$ & $165 \pm 6$ \\
point & $144 \pm 2$ & $194 \pm 6$ & $131 \pm 6$ & $187 \pm 4$ \\
\hline Age at 25th percentile survival & 177 & 208 & 150 & 215 \\
\hline Maximum lifespan & & & & \\
\hline
\end{tabular}

Values represent the estimated values \pm standard error (weeks) for the ages at the 50th and 25 th percentile survival points. 
Table 4. Summary of pathological findings of wild-type (WT) and FoxO1-KO heterozygotic (HT) mice fed ad libitum (AL) or a calorie-restricted $(\mathrm{CR})$ diet

\begin{tabular}{|c|c|c|c|c|}
\hline \multirow[b]{2}{*}{ Group (n) } & \multicolumn{2}{|c|}{ Probable cause of death } & \multicolumn{2}{|c|}{ Number of mice bearing } \\
\hline & Neoplastic & Non-neoplastic & tumors & lymphoma \\
\hline WT-AL (17) & 13 & 4 & 16 & 10 \\
\hline WT-CR (18) & $3^{\mathrm{a}}$ & $15^{\mathrm{a}}$ & $3^{a}$ & $3^{b}$ \\
\hline HT-AL (20) & 16 & 4 & 16 & 12 \\
\hline HT-CR (18) & 10 & 8 & 10 & 8 \\
\hline
\end{tabular}

The total number of rats examined pathologically in each group is in parenthesis. ${ }^{\mathrm{a}}, \mathrm{p}<0.05$ versus (vs) WT-AL, HT-AL, HT-CR. ${ }^{\mathrm{b}}, \mathrm{p}<0.05$ vs WT-AL in each row. The incidence of tumors is also described in Supplemental Table 2. 


\section{Figure legends}

Figure 1. Body weight (A) and food intake (B) of mice in the longevity study. Wild-type (WT) and FoxO1-knockout heterozygotic (HT) male mice were fed ad libitum (AL) or calorie-restricted (CR) diets from 12 weeks of age. (A) The lines represent the mean body weights for each group. Standard deviation bars were omitted for clarity; the coefficient of variation for each group was generally within $15 \%$. The initial numbers of mice in the longevity groups were 19, 23, 25 and 20 in the WT-AL, WT-CR, HT-AL and HT-CR groups, respectively. Data are not depicted when the number of mice was below five. (B) The bars represent the means + standard deviation for 10 mice.

Figure 2. Blood glucose (A) and plasma insulin (B) concentrations, and quantitative insulin sensitivity check index (QUICKI) (C) in the lifespan study. Wild-type (WT) and FoxO1-knockout heterozygotic (HT) male mice were fed ad libitum (AL) or calorie-restricted (CR) diets from 12 weeks of age. The bars represent the means + standard error of 8 to10 mice. Blood glucose and plasma insulin concentrations were measured during the normal feeding cycle. The QUICKI was derived from the following equation: QUICKI $=1 /\left[\log \left(\mathrm{I}_{0}\right)+\log \left(\mathrm{G}_{0}\right)\right]$, where $\mathrm{I}_{0}$ is fasting insulin $(\mathrm{mIU} / \mathrm{ml})$ and $\mathrm{G}_{0}$ is fasting glucose $(\mathrm{mg} / \mathrm{dL})$.

Figure 3. mRNA expression levels of FoxO1 target genes in the liver and hippocampus in response to oxidative stress. Wild-type (WT) and FoxO1-knockout heterozygotic (HT) mice were fed ad libitum (AL) or calorie-restricted (CR) diets. The time points represent 
the time after intraperitoneal injection of 3-nitropropionic acid. The bars represent means + standard error of $3 ? 6$ mice. The mean values are relative to those of the WT-AL group at $0 \mathrm{~min}$. The statistical analyses by three-factor analysis of variance are summarized in Table $2 .^{*}, \mathrm{p}<0.05$ by unpaired t-test. Statistical symbols are only shown for differences between the WT and HT mice in each diet group at each time point. p values less than 0.06 are also noted to suggest tendencies.

Figure 4. Effect of oxidative stress on FoxO1 protein abundance in the hepatic nuclear fraction. Wild-type (WT) and FoxO1-knockout heterozygotic (HT) mice were fed ad libitum (AL) or calorie-restricted (CR) diets. The time points represent the time after intraperitoneal injection of 3-nitropropionic acid. (A) Western blots for FoxO1. PC, positive control. (B) Quantitative analysis of Western blots. The bars represent means + standard error of four mice. The mean values are relative to those of the WT-AL group at 0 min. *, $p<0.05$ by unpaired t-test. Statistical symbols are only shown for differences between the WT and HT mice in each diet group at each time point.

Figure 5. Effect of oxidative stress on $\mathrm{p} 21$ protein abundance in the hepatic nuclear fraction. Wild-type (WT) and FoxO1-knockout heterozygotic (HT) mice were fed ad libitum $(\mathrm{AL})$ or calorie-restricted $(\mathrm{CR})$ diets. The time points represent the time after intraperitoneal injection of 3-nitropropionic acid. (A) Western blots for p21. PC, positive control. (B) Quantitative analysis of Western blots are only presented at $240 \mathrm{~min}$, because those at 0 and 60 min were within the background levels. The bars represent means + standard error of four mice. The mean values are relative to those in the WT-AL group. *, 
$\mathrm{p}<0.05$ by unpaired t-test versus the WT-AL, HT-AL and HT-CR groups.

Figure 6. Survival curves. Wild-type (WT) and FoxO1-knockout heterozygotic (HT) male mice were fed ad libitum (AL) or calorie-restricted (CR) diets from 12 weeks of age. The initial numbers of mice in each group is as follows: WT-AL, 19; WT-CR, 23; HT-AL, 25; HT-CR, 20 
Figure 1.
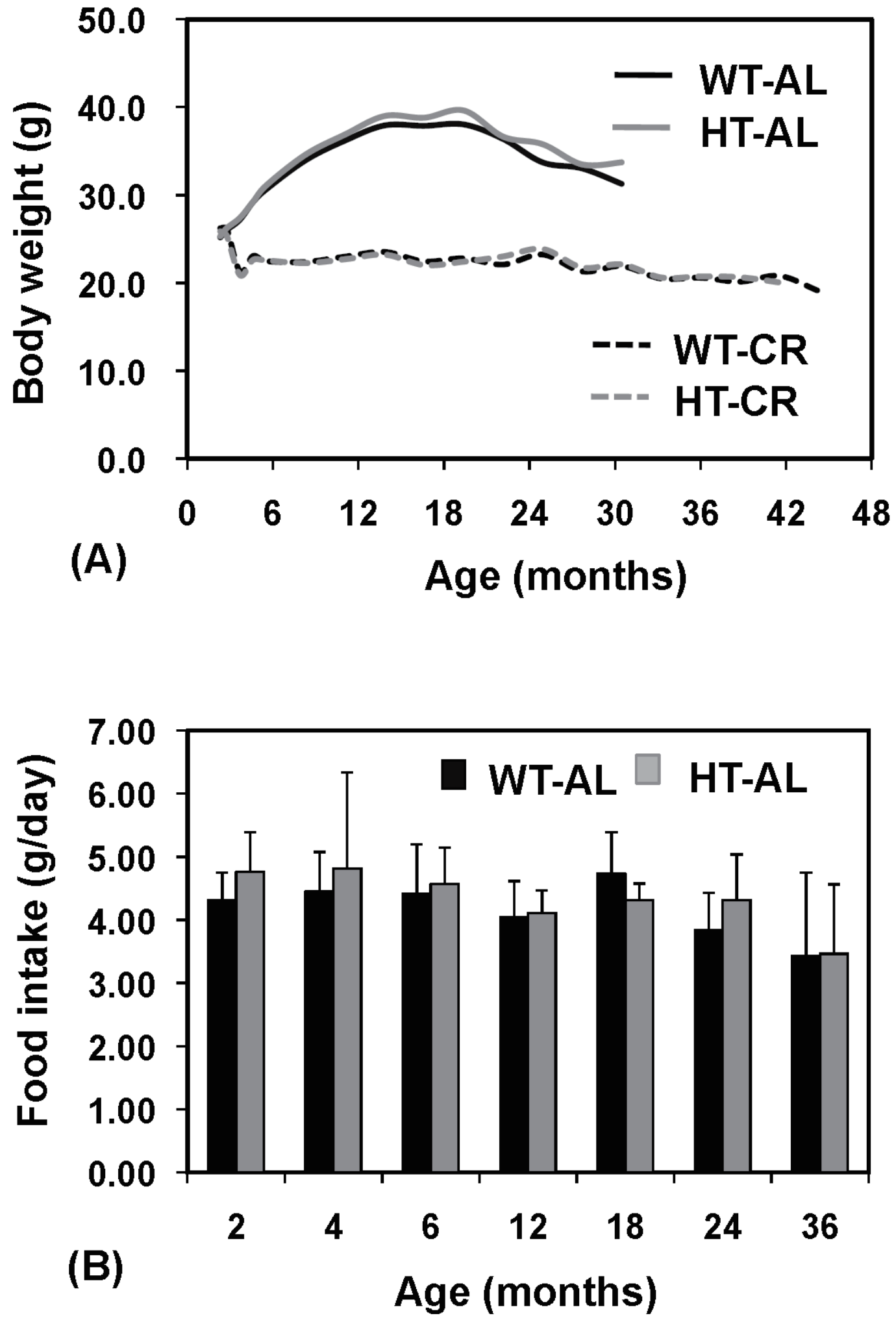
Figure 2.
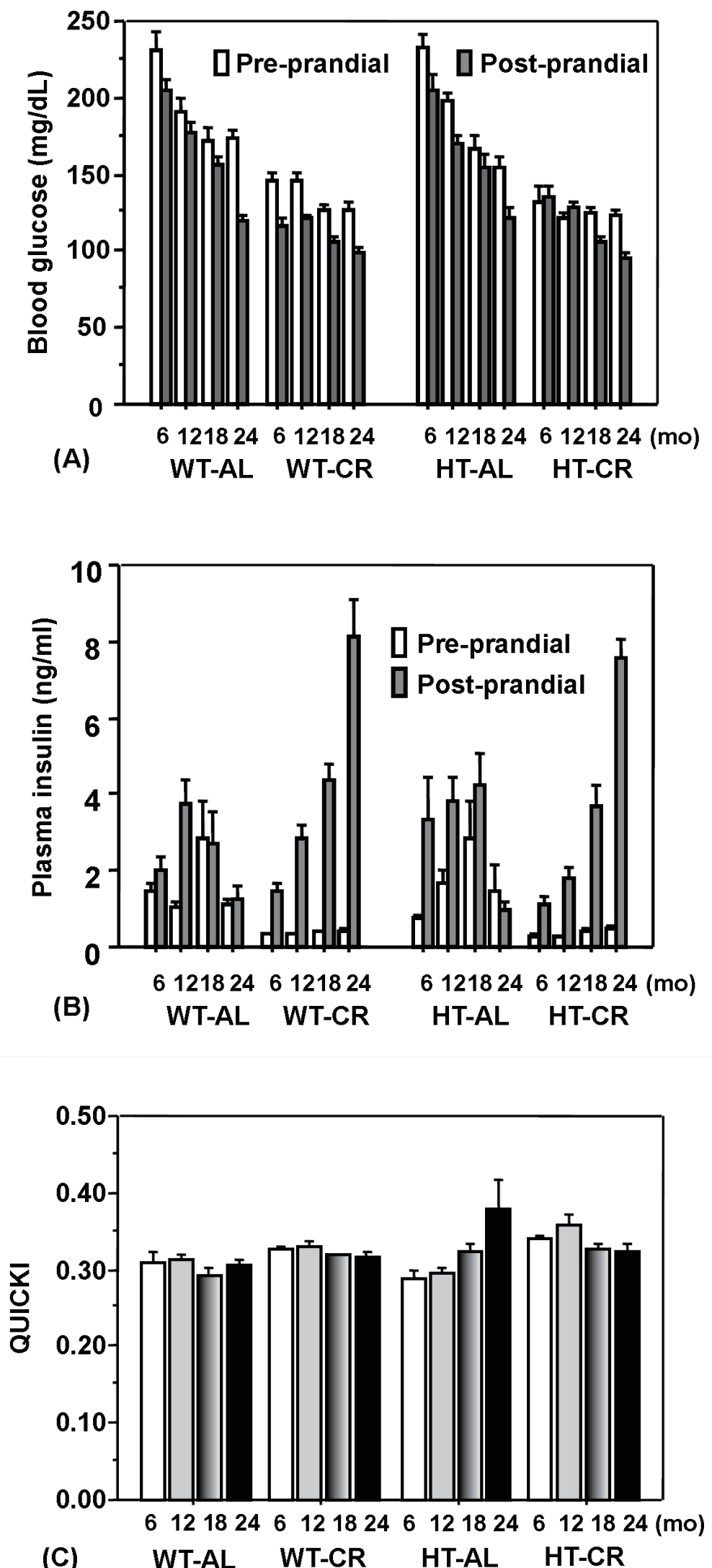
Figure 3.

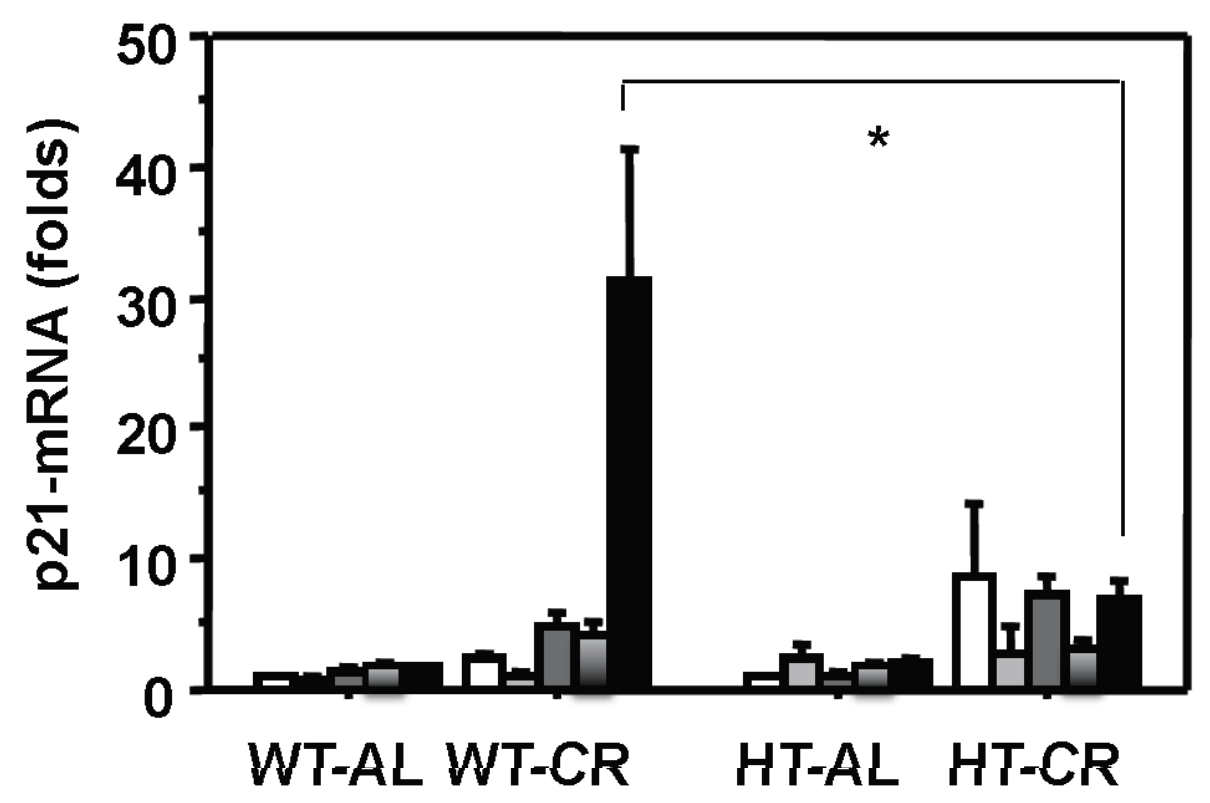

(A) Liver

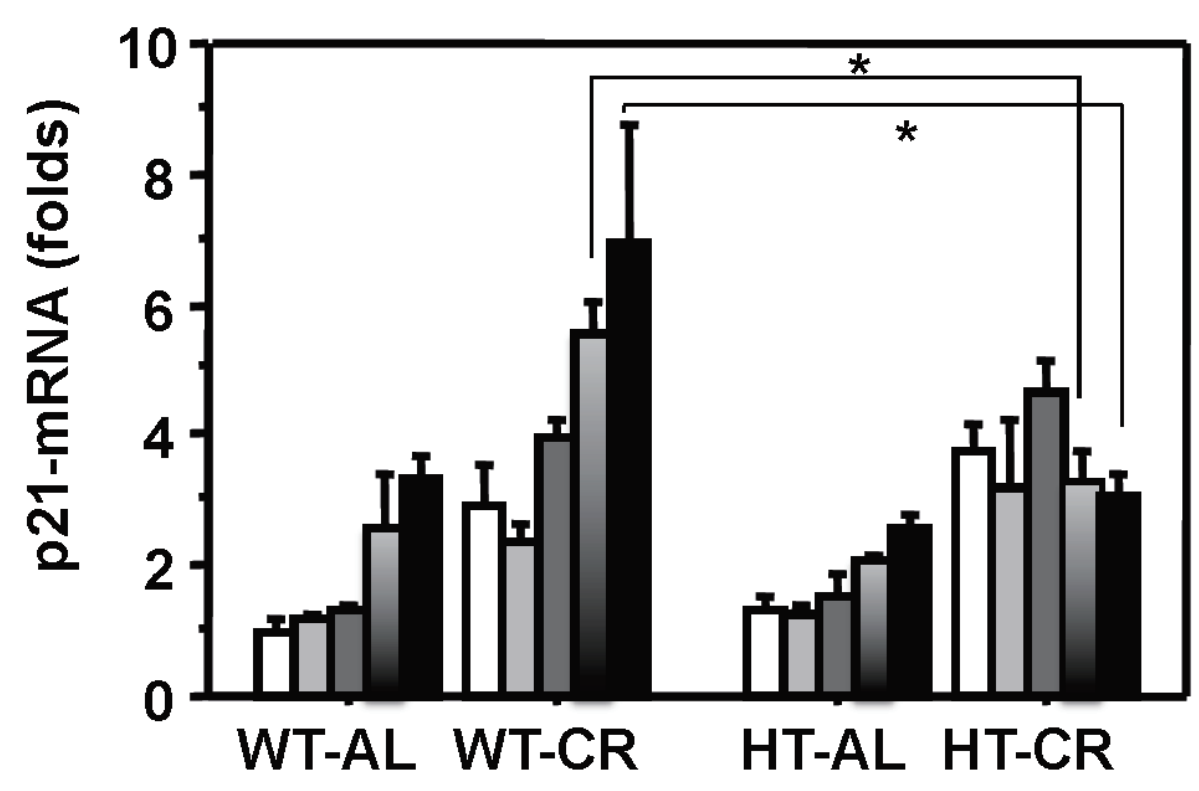

$\square \quad 0$

15

30

60

240

(min)

(B) Hippocampus 


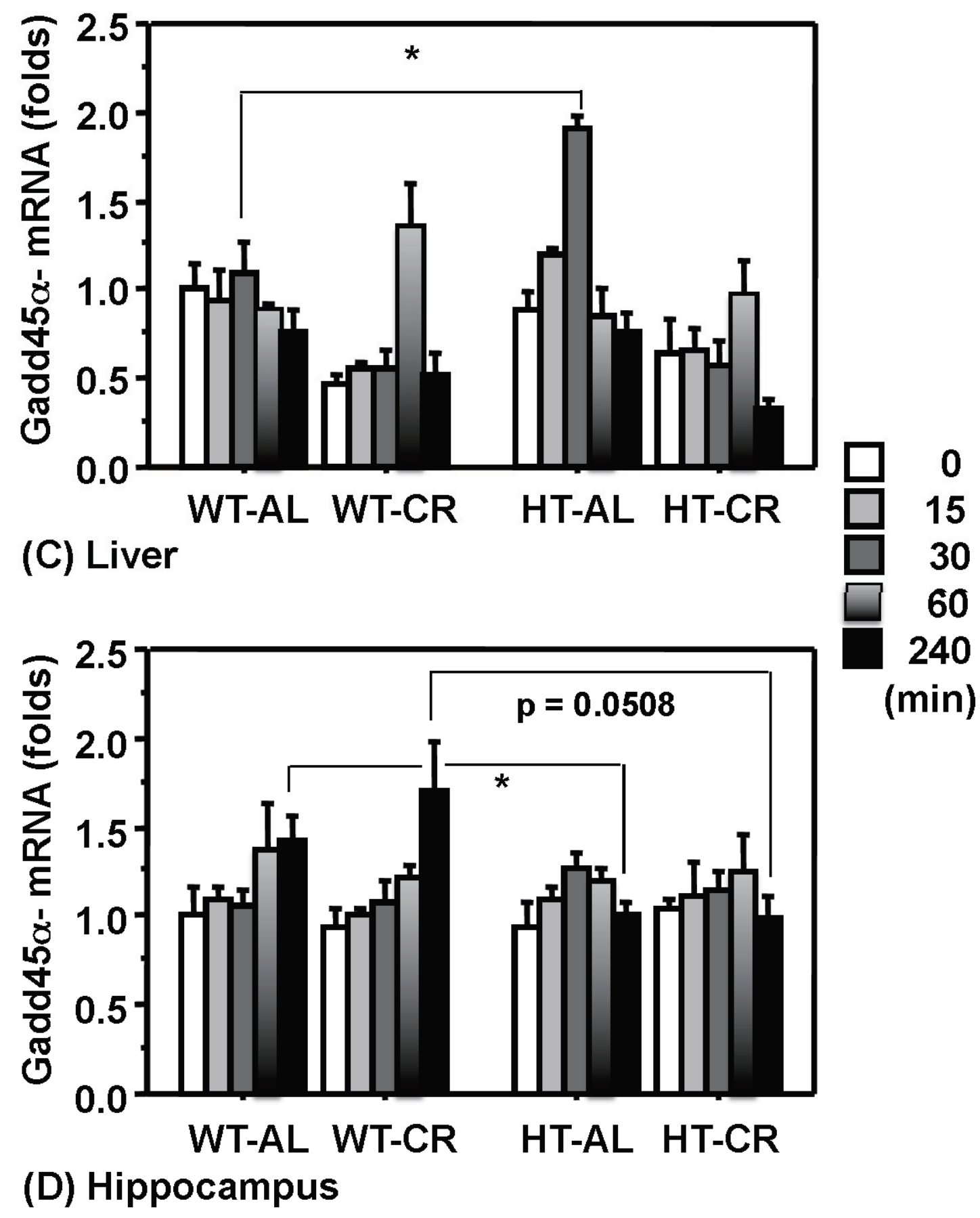




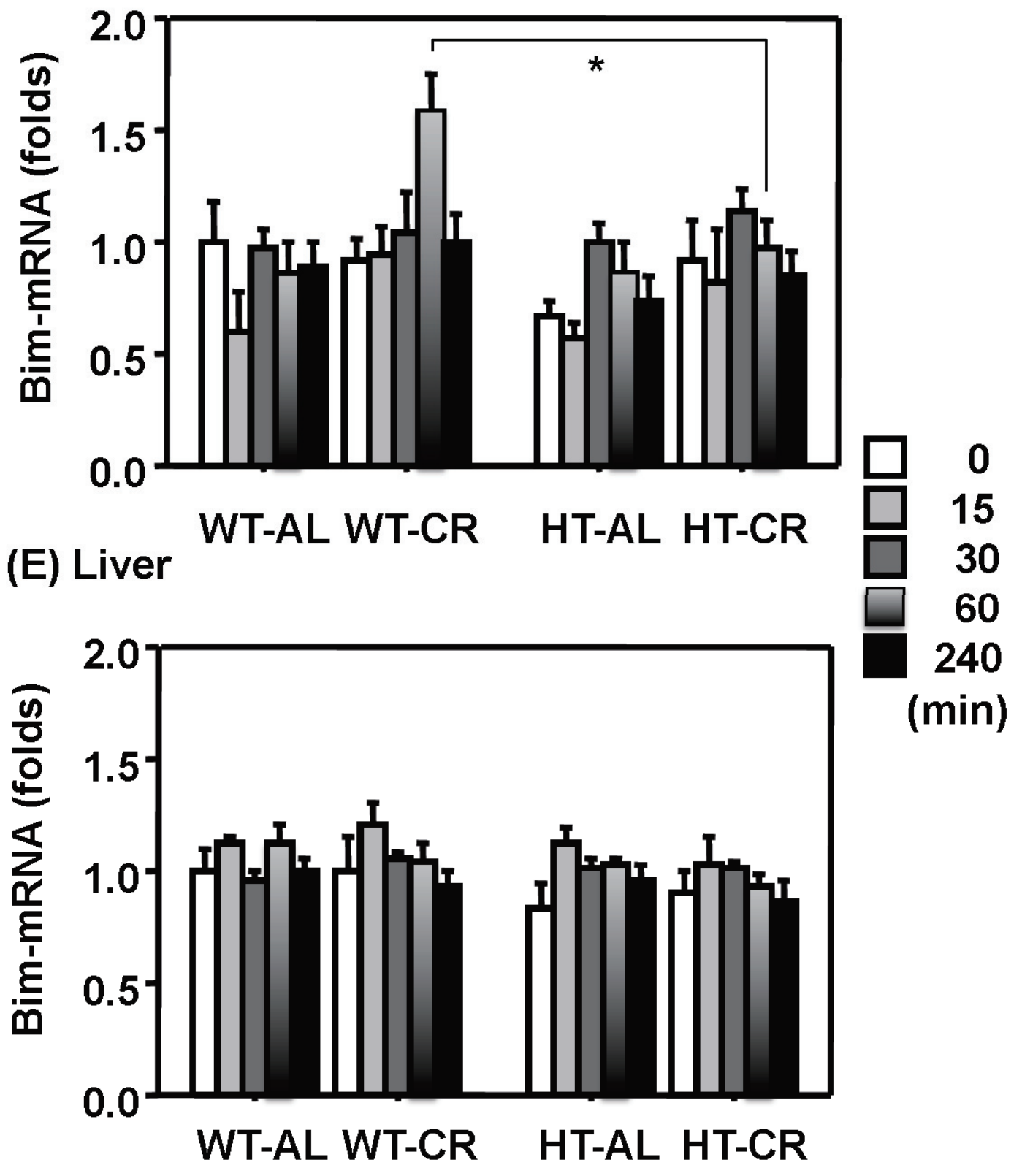

(F) Hippocampus 


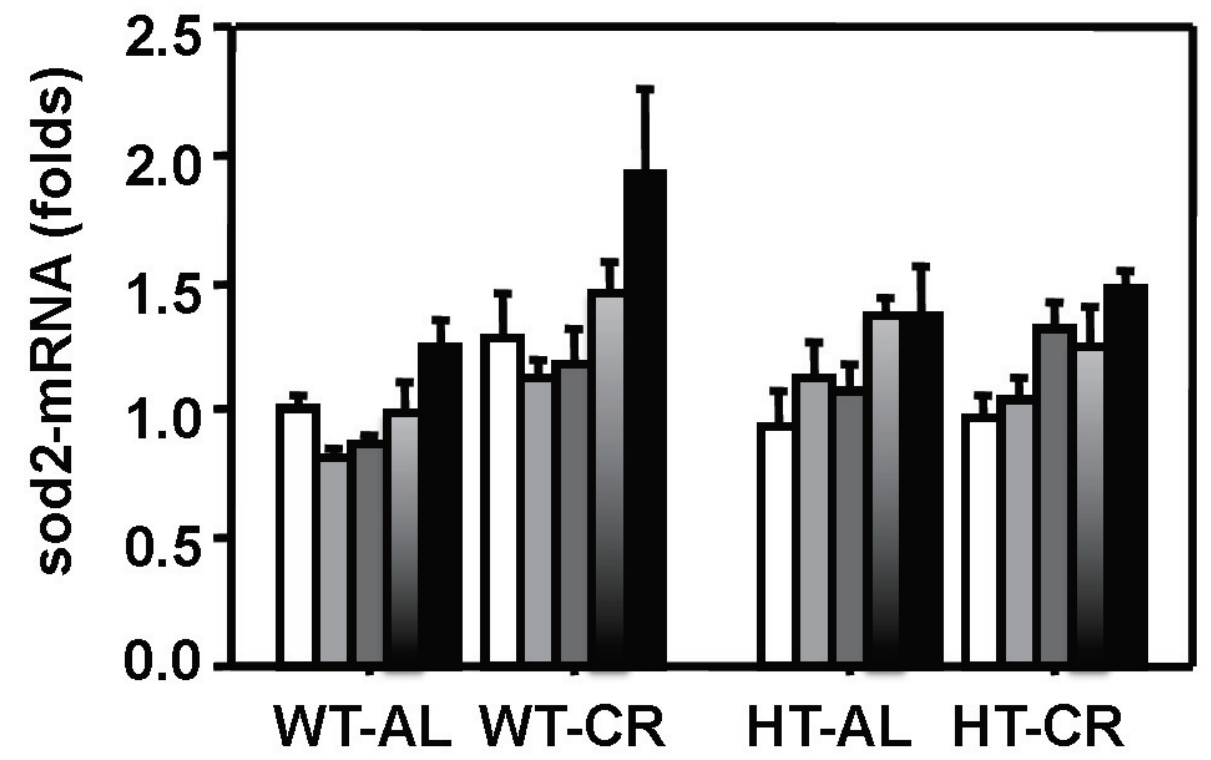

(G) Liver

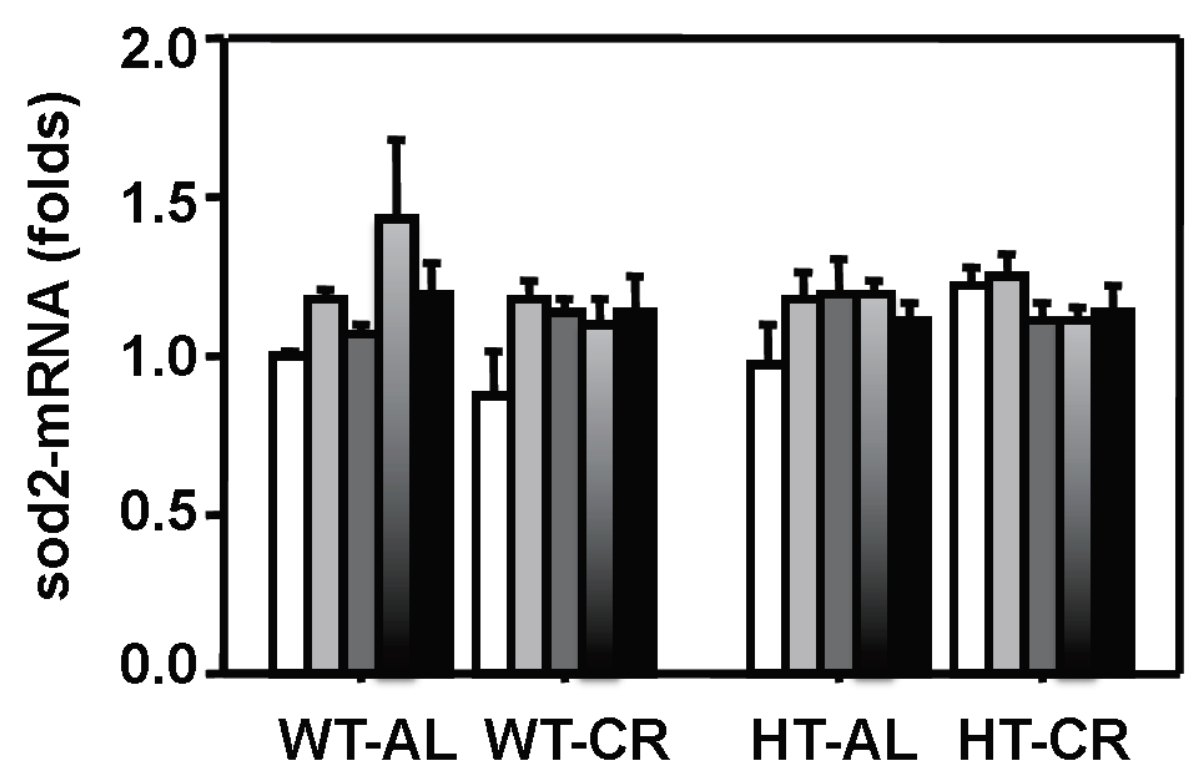

$\square$
$\square \quad 15$

30

60

240

(min)

(H) Hippocampus 

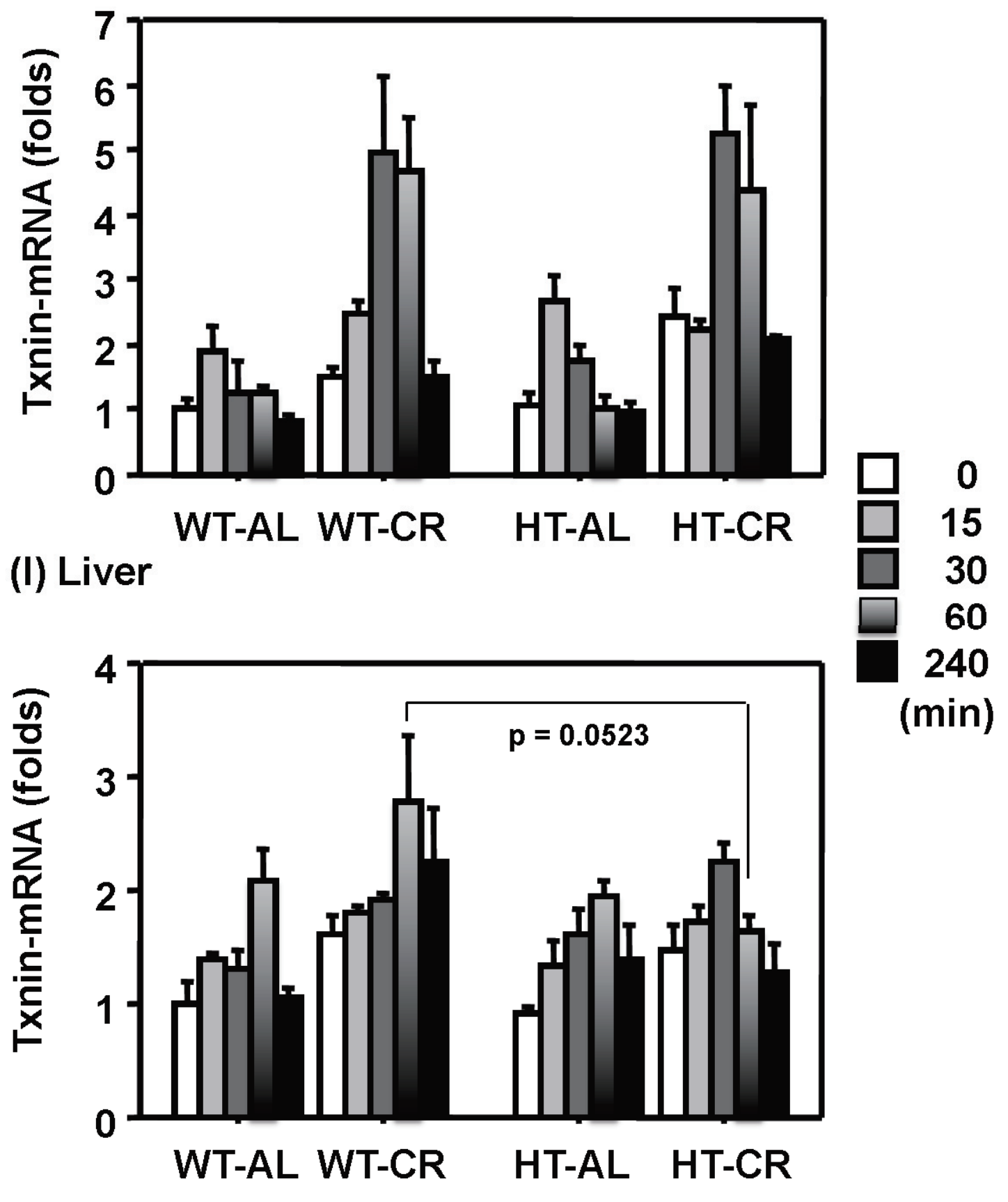

(J) Hippocampus

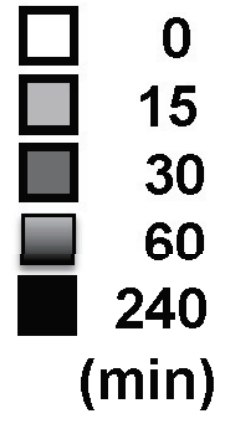


Figure 4.

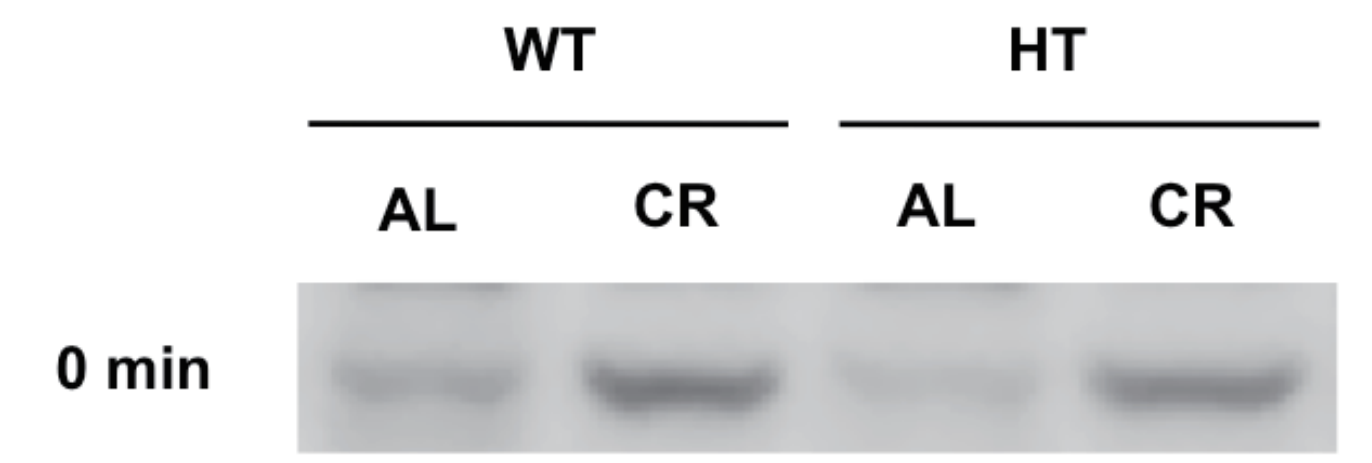

$60 \mathrm{~min}$

$240 \mathrm{~min}$

(A)

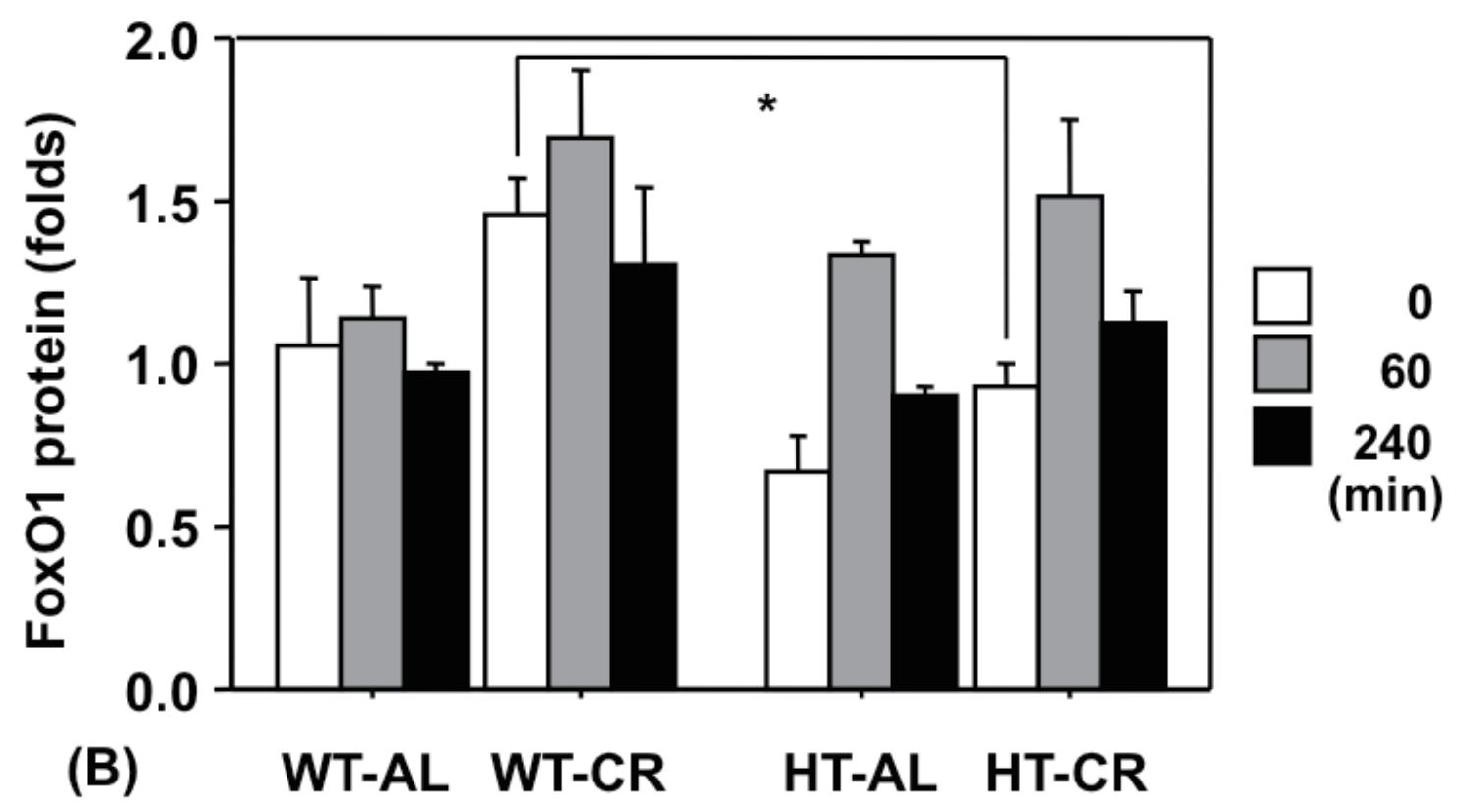


Figure 5.

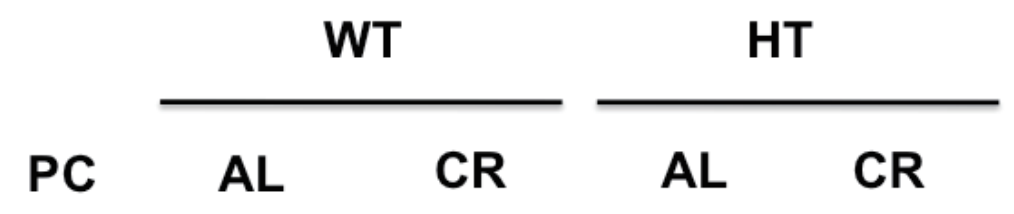

$0 \mathrm{~min}$

$60 \mathrm{~min}$

$240 \mathrm{~min}$

$\leftarrow$ p21

(A)

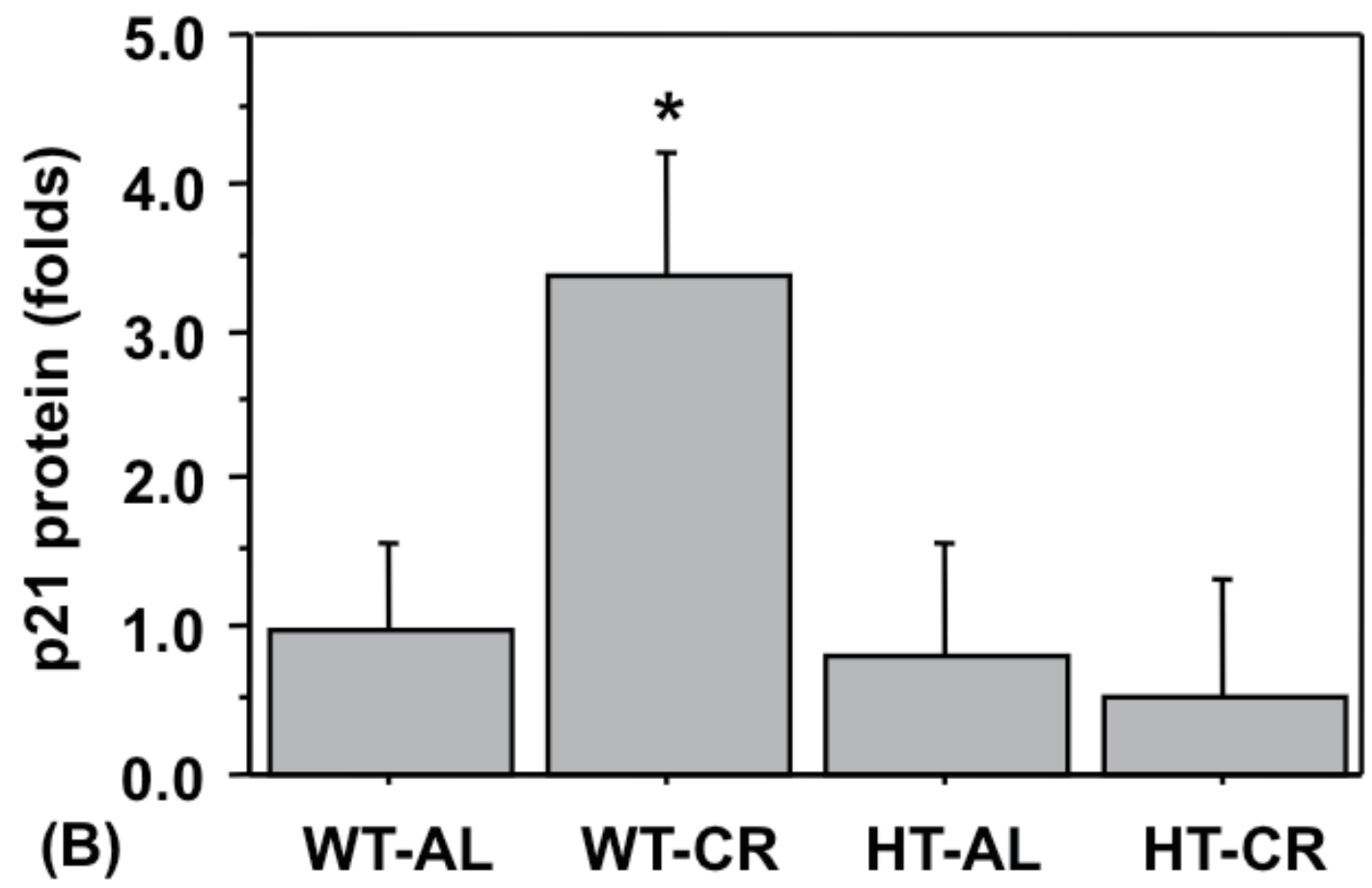


Figure 6.

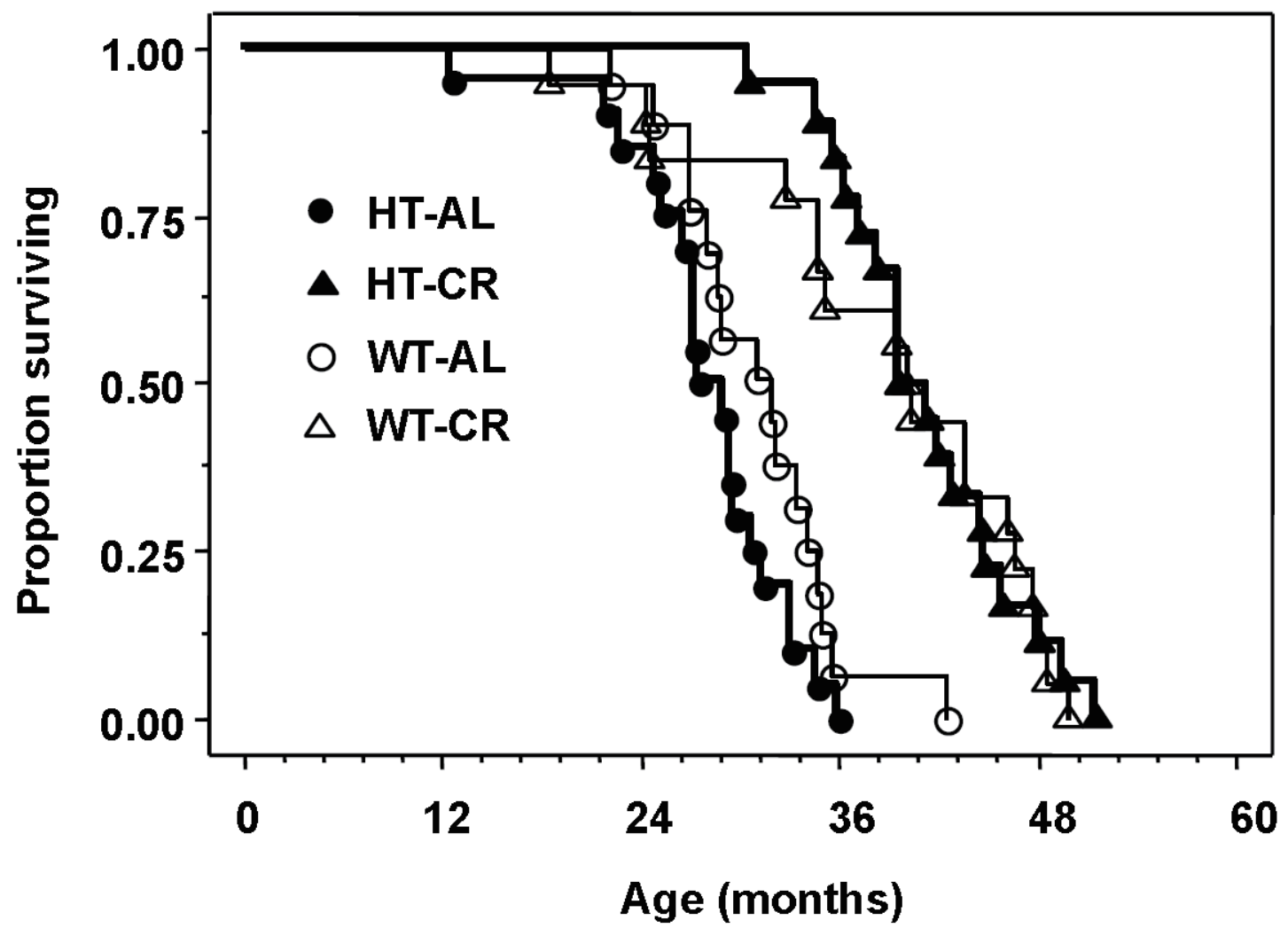


Supplemental figure legends

Supplemental Figure 1. Effect of oxidative stress on the mRNA expression levels of $\beta$-actin in the liver (A) and cyclophilin in the hippocampus (B). Wild-type (WT) and FoxO1-knockout heterozygotic (HT) mice were fed ad libitum (AL) or calorie-restricted (CR) diets. The time points represent the time after intraperitoneal injection of 3-nitropropionic acid. The bars represent means + standard error of 3-6 mice. The mean values are relative to those of the WT-AL group at $0 \mathrm{~min}$. The statistical analyses by three-factor analysis of variance are summarized in Table 2.

Supplemental Figure 2. Effect of oxidative stress on mRNA expression levels of FoxO1 target genes (p27 and catalase) in the liver and hippocampus. Wild-type (WT) and FoxO1-knockout heterozygotic (HT) mice were fed ad libitum (AL) or calorie-restricted (CR) diets. The time points represent the time after intraperitoneal injection of 3-nitropropionic acid. The bars represent means + standard error of 3-6 mice. The mean values are relative to those of the WT-AL group at $0 \mathrm{~min}$. The statistical analyses by three-factor analysis of variance are summarized in Table 2. *, p $<0.05$ by unpaired t-test. Statistical symbols are only shown for differences between the WT and HT mice in each diet group at each time point. 
Supplemental Figure 3. Ponceau S staining of a PVDF membrane and Western blots of TATA binding protein (TBP) in the hepatic nuclear fraction for Western blots for FoxO1. Wild-type (WT) and FoxO1-knockout heterozygotic (HT) mice were fed ad libitum (AL) or calorie-restricted (CR) diets. (A) A representative membrane stained by Ponceau S. (B) Quantitative analysis of the total intensity of bands in each lane. The time points represent the time after intraperitoneal injection of 3-nitropropionic acid (NPA). The bars represent means + standard error of four mice. Three-factor ANOVA showed no significant effect of Genotype, Diet or Time. (C) A representative Western blot for TBP. (D) Quantitative analysis of Western blots for TBP. The bars represent means + standard error of four mice. The TBP protein abundance was increased after 3-NPA injection (Time, $\mathrm{p}<0.0001$ ). The abundance was lower in the CR groups than in the AL groups (Diet, $\mathrm{p}=0.0001$ ). There was no difference between the WT and HT mice. The results obtained with Ponceau S staining for TBP and Western blotting for p21 were similar to those for FoxO1 (data not shown). 
Supplemental Figure 1.

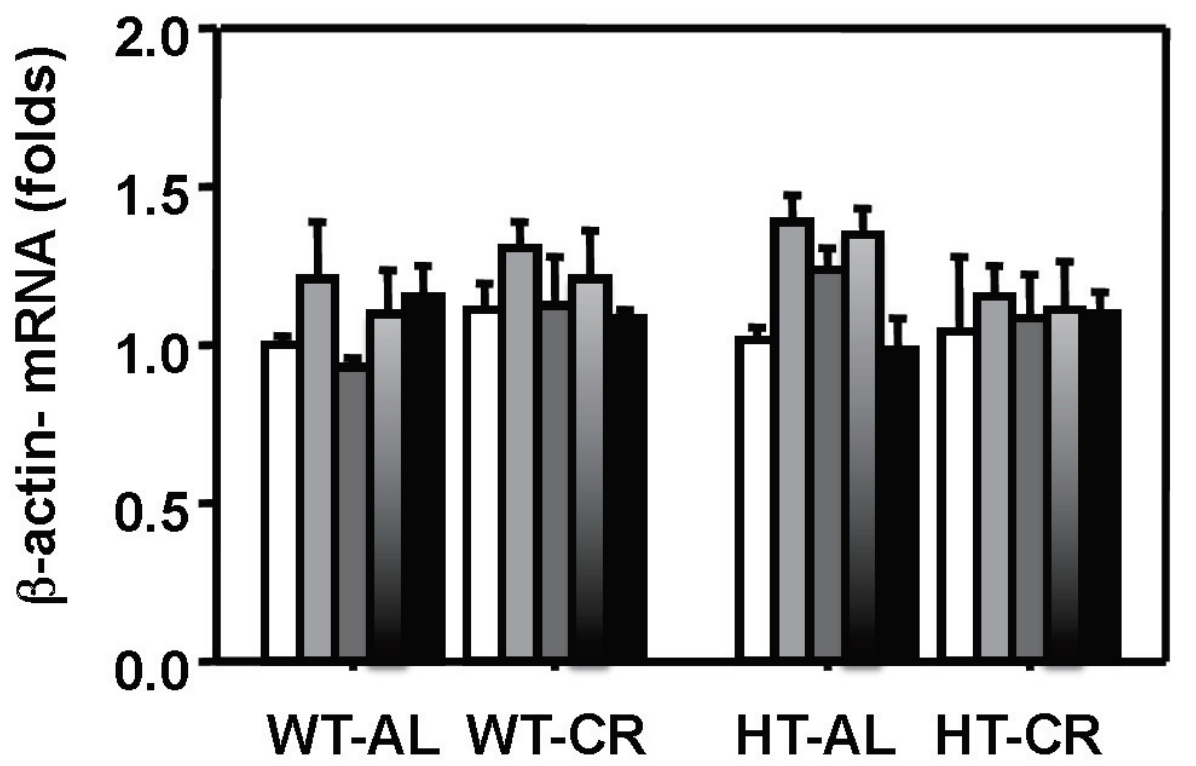

A) Liver
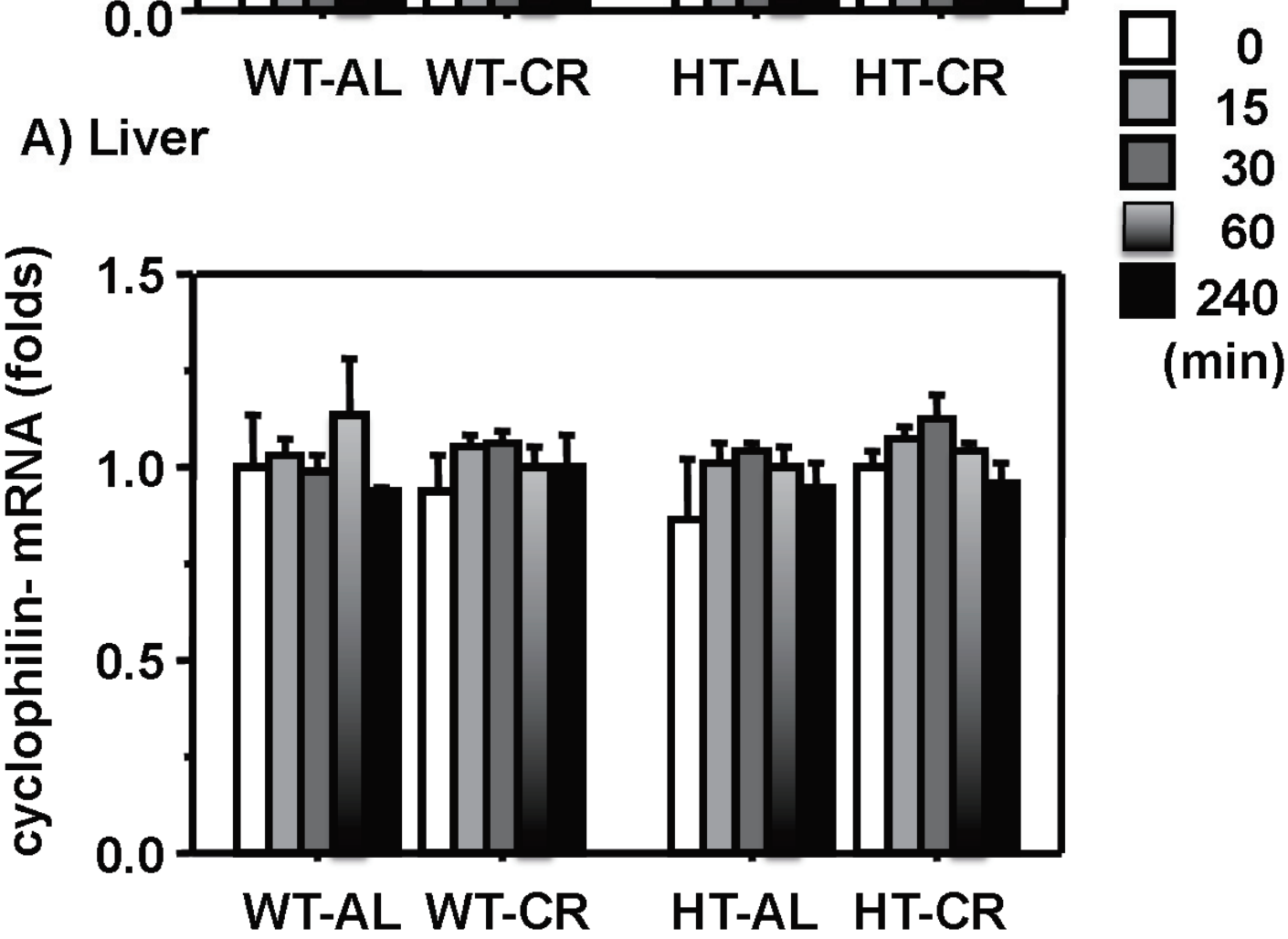

B) Hippocampus 
Supplemental Figure 2.

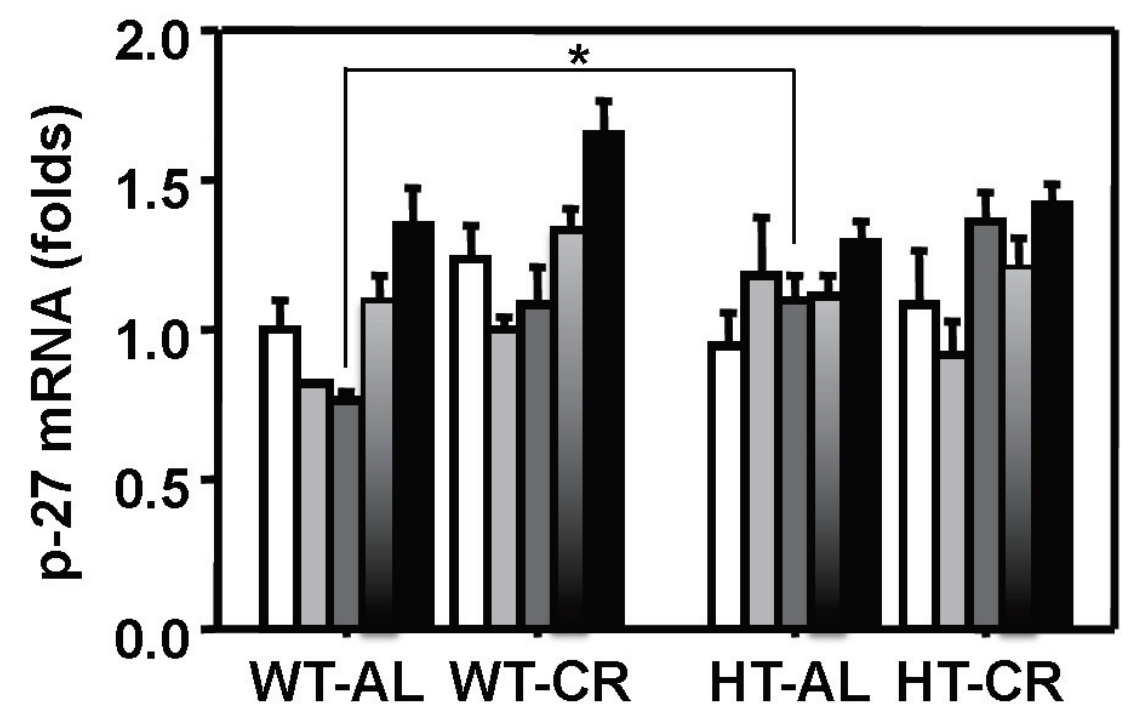

A) Liver

$\square \quad \begin{array}{r}0 \\ 15\end{array}$

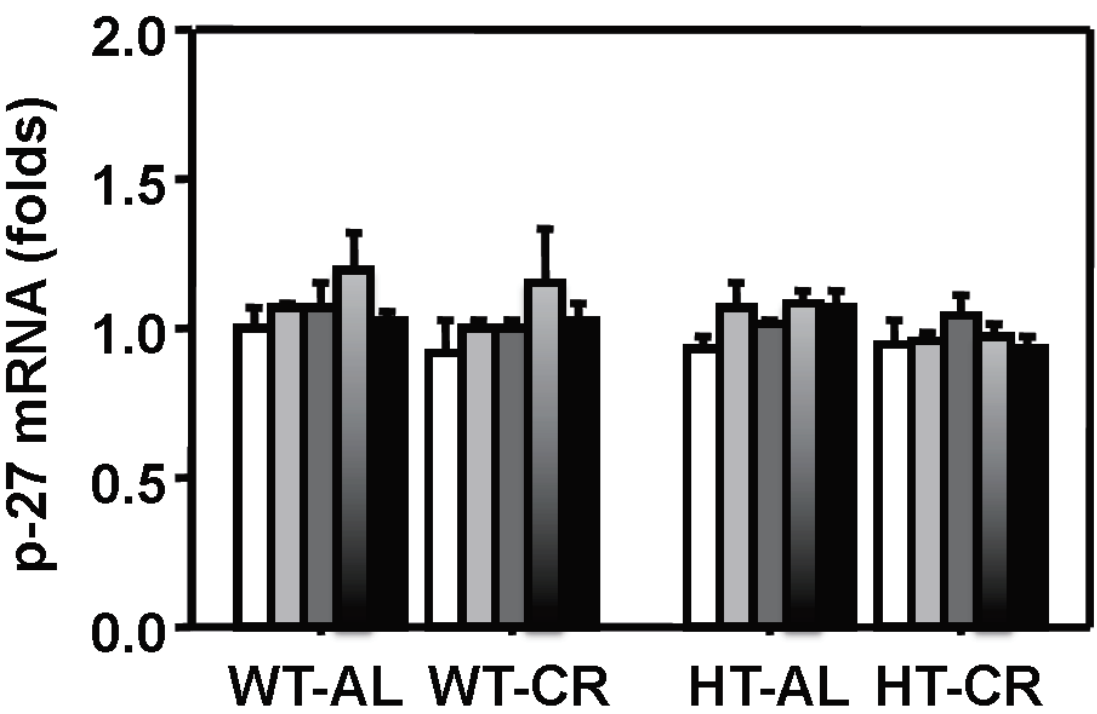

B) Hippocampus 


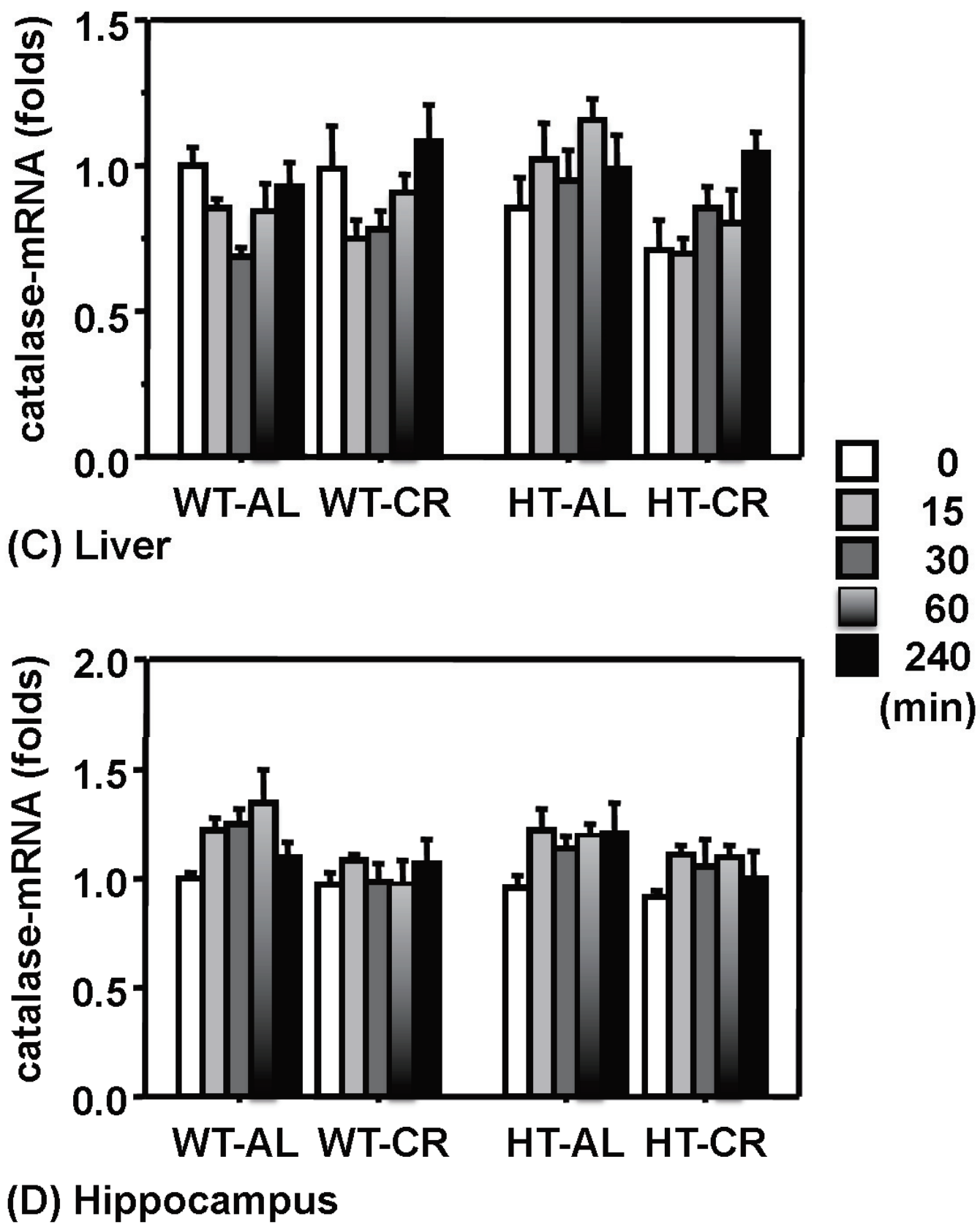


Supplemental Figure 3.

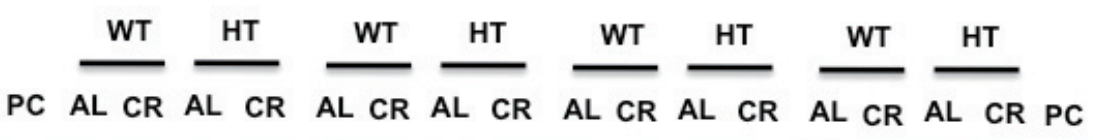

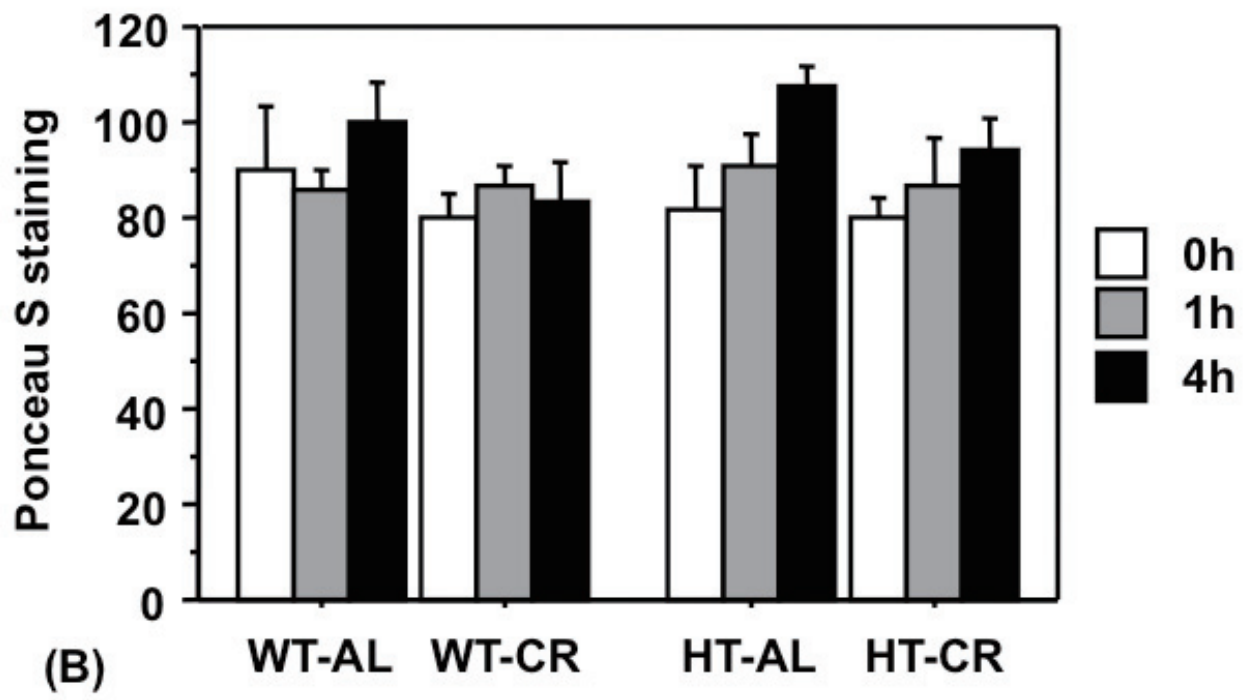




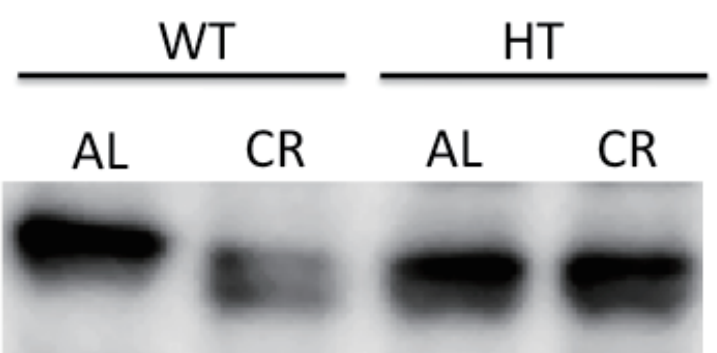

0 min

$60 \mathrm{~min}$

$240 \mathrm{~min}$

(C)

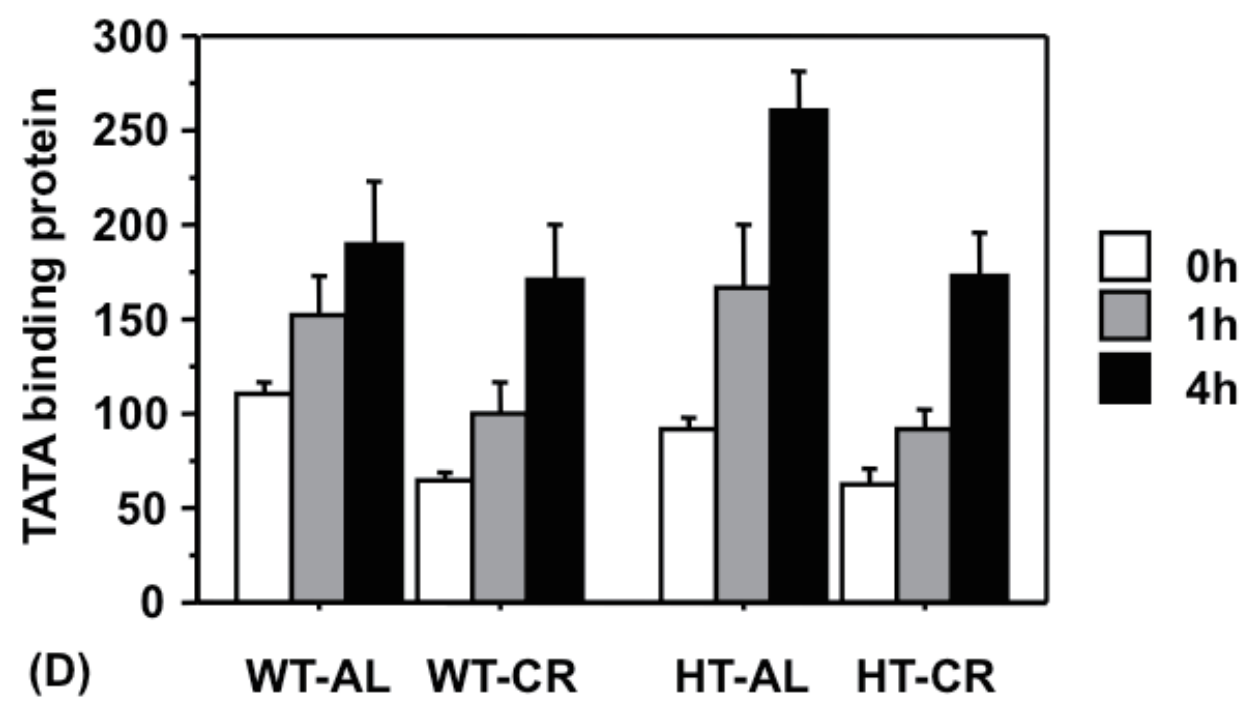

